This document was prepared in conjunction with work accomplished under Contract No. DE-AC09-96SR18500 with the U. S. Department of Energy.

\title{
DISCLAIMER
}

This report was prepared as an account of work sponsored by an agency of the United States Government. Neither the United States Government nor any agency thereof, nor any of their employees, nor any of their contractors, subcontractors or their employees, makes any warranty, express or implied, or assumes any legal liability or responsibility for the accuracy, completeness, or any third party's use or the results of such use of any information, apparatus, product, or process disclosed, or represents that its use would not infringe privately owned rights. Reference herein to any specific commercial product, process, or service by trade name, trademark, manufacturer, or otherwise, does not necessarily constitute or imply its endorsement, recommendation, or favoring by the United States Government or any agency thereof or its contractors or subcontractors. The views and opinions of authors expressed herein do not necessarily state or reflect those of the United States Government or any agency thereof. 


\section{GLASS MACROCRACKING DETERMINATION IN PROTOTYPIC CANISTERS CONTAINING LANTHANIDE BOROSILICATE GLASS}

Timothy Jones

James Marra

David Immel

Ben Meers

January 2006

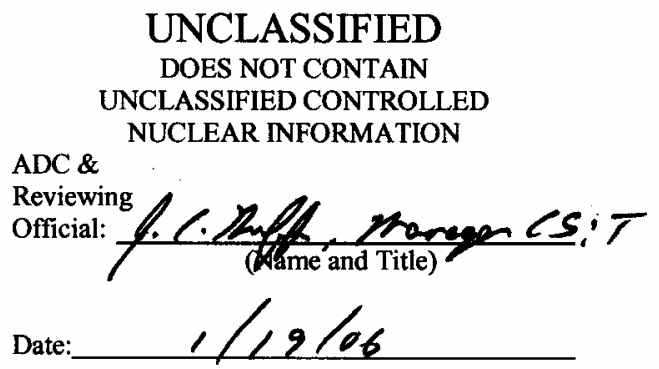




\title{
DISCLAIMER
}

This report was prepared by Washington Savannah River Company (WSRC) for the United States Department of Energy under Contract No. DE-AC09-96SR18500 and is an account of work performed under that contract. Neither the United States Department of Energy, nor WSRC, nor any of their employees makes any warranty, expressed or implied, or assumes any legal liability or responsibility for the accuracy, completeness, or usefulness, of any information, apparatus, or product or process disclosed herein or represents that its use will not infringe privately owned rights. Reference herein to any specific commercial product, process, or service by trademark, name, manufacturer or otherwise does not necessarily constitute or imply endorsement, recommendation, or favoring of same by WSRC or by the United States Government or any agency thereof. The views and opinions of the authors expressed herein do not necessarily state or reflect those of the United States Government or any agency thereof.

\author{
Printed in the United States of America \\ Prepared For \\ U.S. Department of Energy
}


Key Words: plutonium, vitrification, surface area

Retention: Permanent

\section{GLASS MACROCRACKING DETERMINATION IN PROTOTYPIC CANISTERS CONTAINING LANTHANIDE BOROSILICATE GLASS}

Timothy Jones

James Marra

David Immel

Ben Meers

January 2006 
WSRC-TR-2006-00015

Revision 0

\section{REVIEWS AND APPROVALS}

\section{AUTHOR(S):}

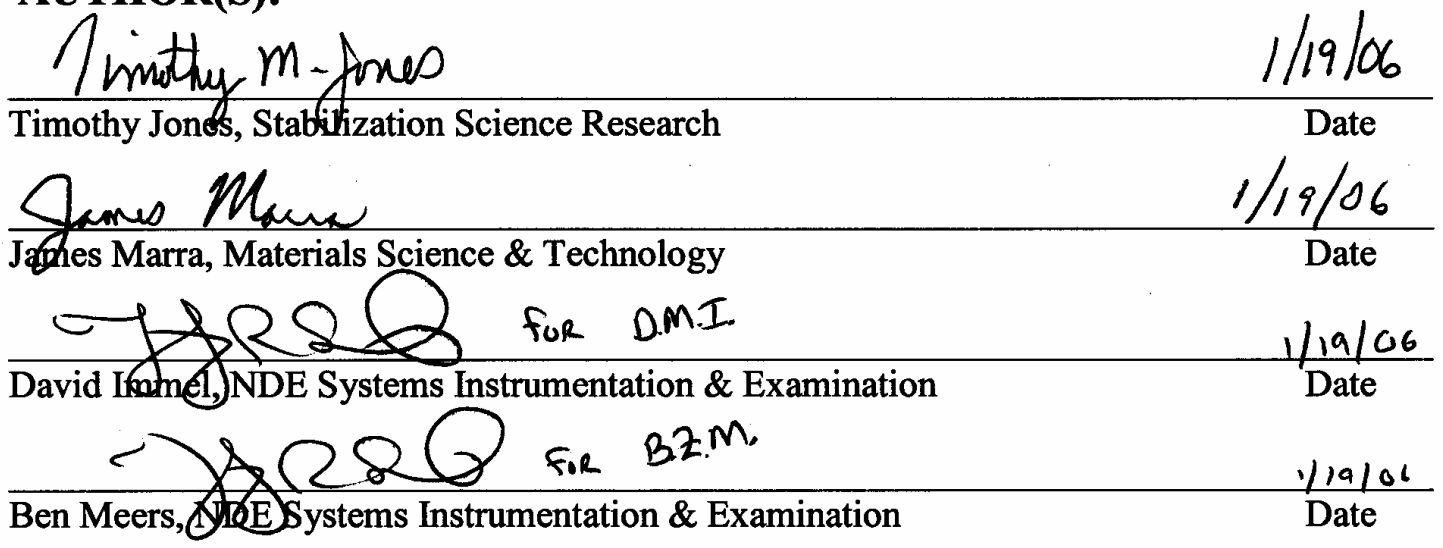

TECHNICAL REVJEWER:

Michef $1 / 19 / 06$

\section{APPROVERS}

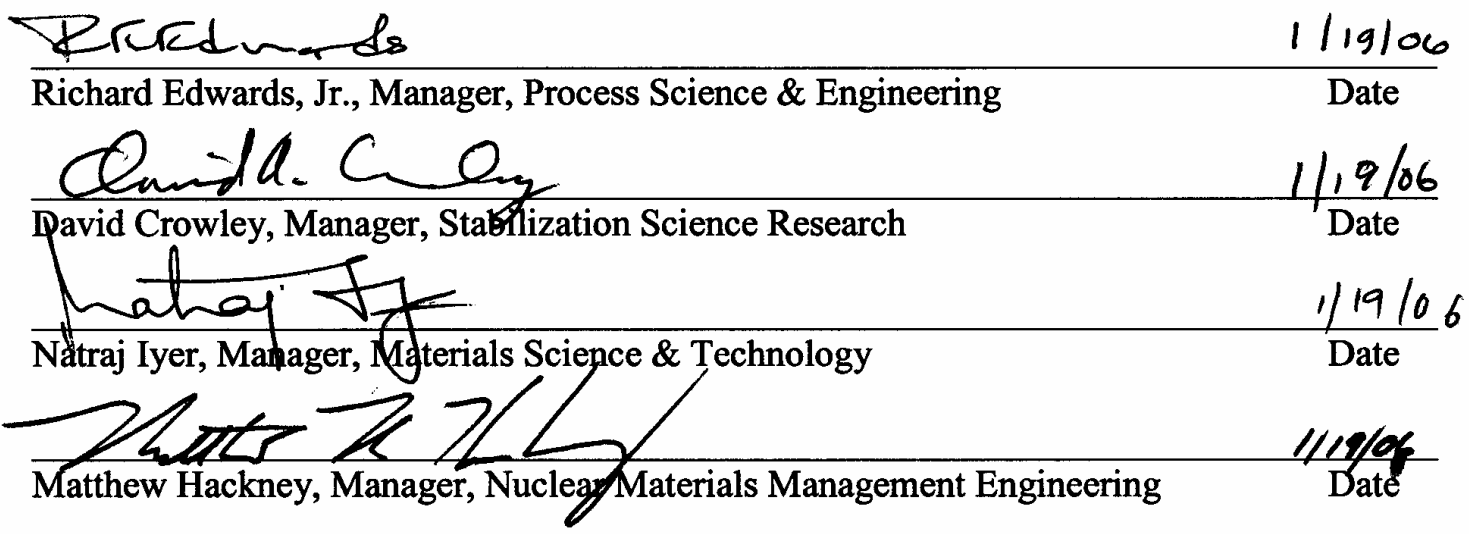




\section{EXECUTIVE SUMMARY}

The Department of Energy Office of Environmental Management (DOE/EM) plans to conduct the Plutonium Disposition Project at the Savannah River Site (SRS) to disposition excess weapons-usable plutonium. Immobilization in a lanthanide borosilicate (LaBS) glass appears to be a viable option for the disposition of the plutonium. Several near-term data needs were identified to help increase confidence that the LaBS glass product is suitable for disposal in the Yucca Mountain Repository. One of these needs was to assess the degree of macroscopic cracking and/or voiding that occurs during processing of the Pu glass waste form and subsequent pouring of high level waste (HLW) glass. This data would then be utilized in repository modeling to provide a value for the actual glass surface area that would be available for leaching. This report summarizes testing and analyses that were completed on prototypic cans of LaBS glass to provide this data.

Prototypic cans were filled with LaBS glass produced in the Cylindrical Induction Melter (CIM), then exposed to a thermal treatment to represent conditions that would be expected during pouring of HLW glass around the Pu glass product cans in the DWPF (Smith, 2000). The cans containing the LaBS glass were subjected to non-destructive evaluation (NDE) and destructive analysis techniques to assess the amount of cracking and/or voiding that occurred during processing.

Testing conducted on large canisters or full-scale DWPF canisters have shown that thermal stresses and glass/canister interactions result in a 7 to 27 times increase in surface area as compared to the monolithic geometric surface area (Peters, 1981). Earlier testing conducted at SRS with simulated HLW glass and smaller diameter canisters $(\sim 20 \mathrm{~cm})$ resulted in a surface area increase of 5 times for canisters allowed to air cool (Kessler, 1982). Testing conducted under this task on stainless steel canisters of 2.87 inch inside diameter indicated thermal stresses and glass/canister interactions result in a 1.9 to 4.1 times increase in surface area due to glass cracking. Comparison of digital radiography images taken of the canisters prior to and after heat treatment suggests most of the cracking occurred as a result of stresses induced by canister deformation during the heat treatment. Dimensional constraints of the heat treatment furnace required the prototypic canisters be positioned horizontally during the heat treatment process, resulting in a slight "flattening" of the canisters, inducing stress in the LaBS glass upon cooling, resulting in cracking. Therefore, this additional cracking was an artifact of the test configuration and not the actual thermal treatment. Digital radiography images also show the presence of only very small voids within the LaBS glass prior to heat treatment, which decreased in number and size during the heat treatment.

The data produced by testing conducted in this task is conservative in that the prototypic canisters were heat treated in a horizontal orientation, rather than vertically as will be the case in actual processing within the DWPF canisters. The cracking can also be reduced in the prototypic canisters by controlling the initial cooling rate as the LaBS glass is poured into the cans. Conservatism in the data is also realized in that the calculations of surface area increases due to glass cracking assume the cracks measured at the exposed surface of each can section extend completely through the length of the section. 


\section{TABLE OF CONTENTS}

EXECUTIVE SUMMARY .................................................................................................

LIST OF FIGURES .............................................................................................................

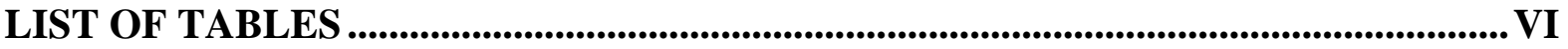

LIST OF ACRONYMS ..................................................................................................... VII

1.0 INTRODUCTION AND BACKGROUND.................................................................. 1

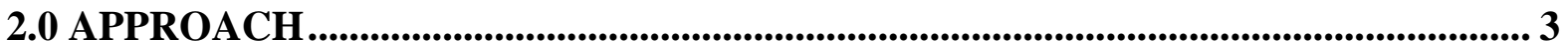

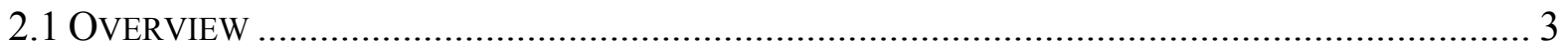

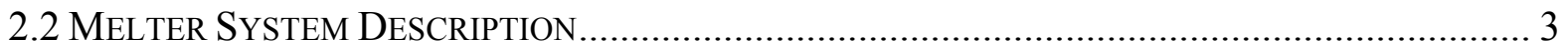

2.3 PRototyPiC PU VITRIFICATION CANISTER DESCRIPTION .................................................... 4

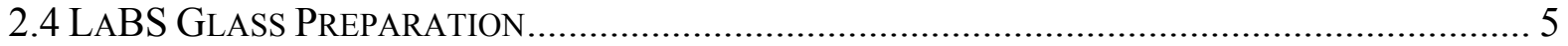

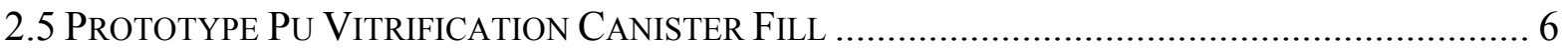

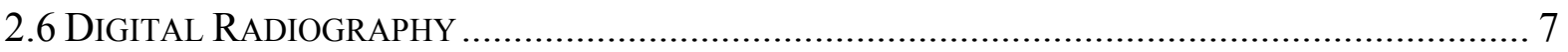

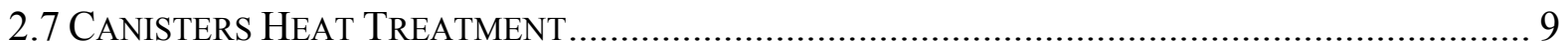

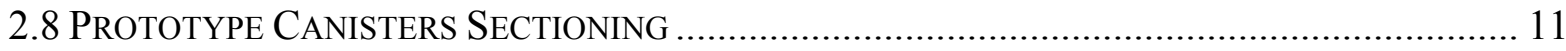

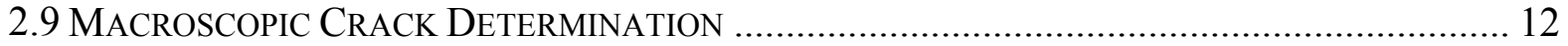

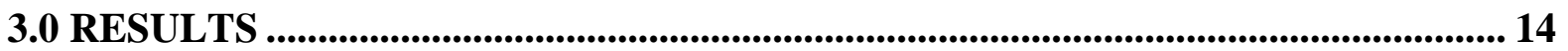

3.1 Macrocracking Surface Area Determination...................................................... 14

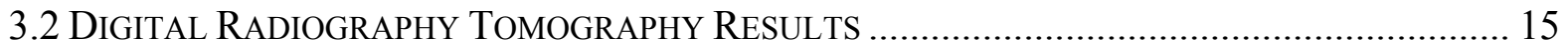

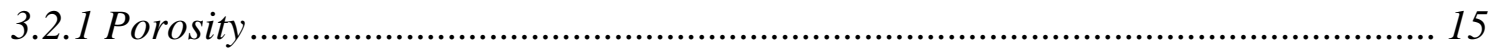

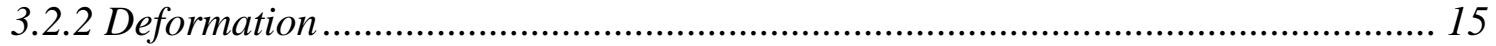

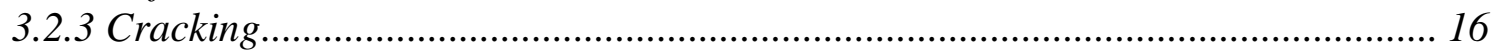

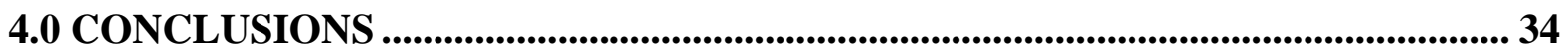

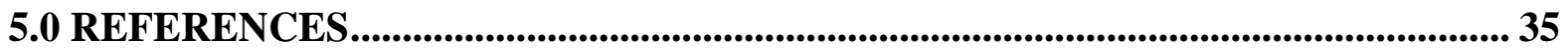

6.0 ACKNOWLEDGEMENTS ......................................................................................... 36

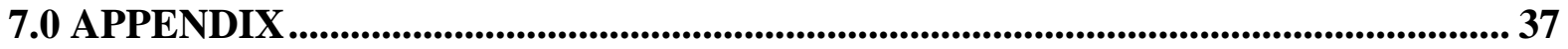

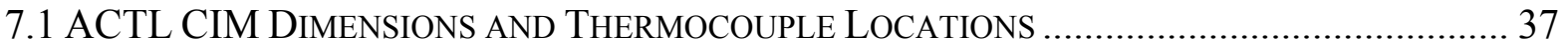

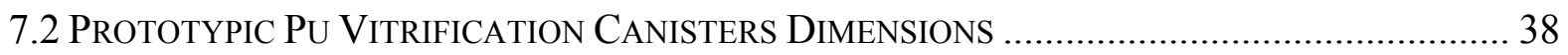

7.3 Prototypic Pu Vitrification CANiSTERS SECTIONEd DiMENSIONS ................................ 39

7.4 PRototyPiC CANISTERS RADIOGRAPHY SECTION DIMENSIONS .......................................... 40 


\section{LIST OF FIGURES}

Figure 1. Cylindrical Induction Melter System .............................................................. 4

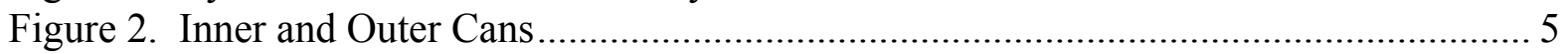

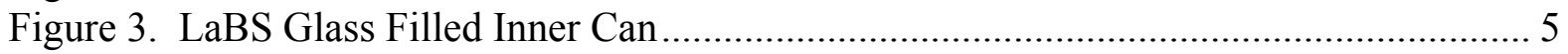

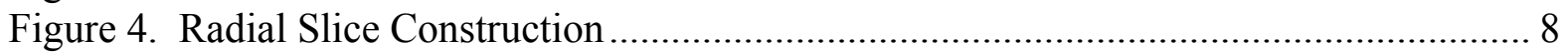

Figure 5. Prototype Canisters Heat Treatment............................................................... 10

Figure 6. Phase 2 Can-In-Canister Cold Pour Tests .............................................................. 10

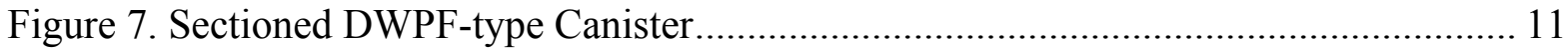

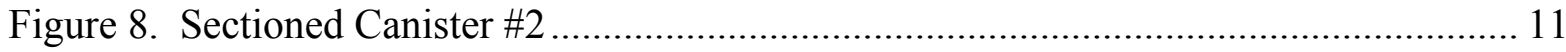

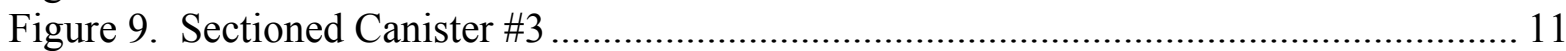

Figure 10. Sectioned Canister \#2 Bottom ........................................................................ 12

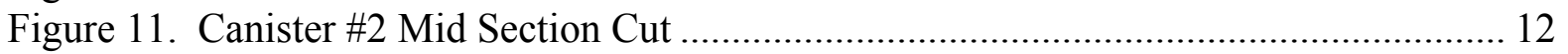

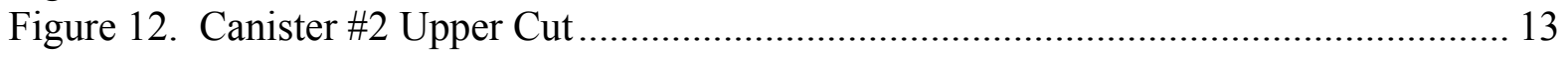

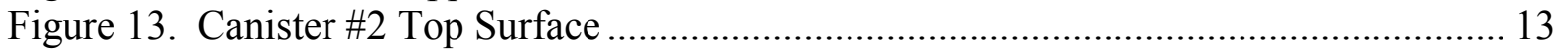

Figure 14. Sectioned Canister \#3 Bottom ......................................................................... 13

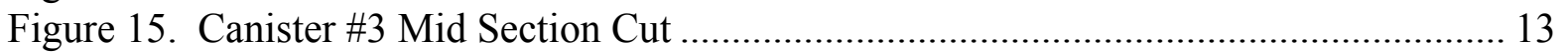

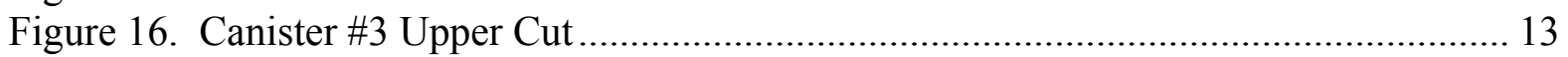

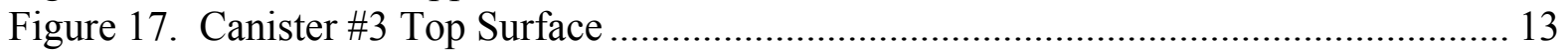

Figure 18. Post-Heat Treated CT slice from Canister \#2 Middle Section ............................. 16

Figure 19. Post-Heat Treated CT slice from Canister \#3 Top Section .................................. 16

Figure 20. Radial Slice Image Explanation ………………................................................. 18

Figure 21. Pre-heat treated and Post-heat treated Canister CT Scans..................................... 19

Figure 22. Canister \#2 Composite CT Generated Radiographs............................................... 20

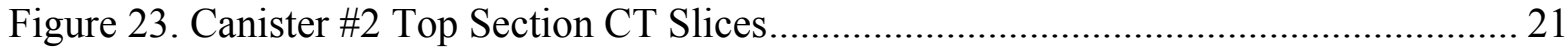

Figure 24. Canister \#2 Middle Section CT Slices.................................................................. 22

Figure 25. Canister \#2 Bottom Section CT Slices ................................................................. 23

Figure 26. Canister \#2 Top Section Vertical Slices ............................................................. 24

Figure 27. Canister \#2 Middle Section Vertical Slices............................................................ 25

Figure 28. Canister \#2 Bottom Section Vertical Slices ............................................................. 26

Figure 29. Canister \#3 Composite CT Generated Radiographs............................................... 27

Figure 30. Canister \#3 Top Section Vertical Slices ............................................................ 28

Figure 31. Canister \#3 Middle Section Vertical Slices........................................................... 29

Figure 32. Canister \#3 Bottom Section Vertical Slices ........................................................ 30

Figure 33. Canister \#3 Top Section Vertical Slices ............................................................. 31

Figure 34. Canister \#3 Middle Section Vertical Slices............................................................. 32

Figure 35. Canister \#3 Bottom Section Vertical Slices ........................................................... 33

\section{LIST OF TABLES}

Table 1. LaBS Frit B Batch $\left(\mathrm{Zr}_{2} \mathrm{O}_{3}\right.$ sub for $\left.\mathrm{PuO}_{2}\right)$ From Commercial Vendor ....................... 6

Table 2. CT Radiographic Setup Parameters ................................................................... 7

Table 3. Examined Can Sections ..................................................................................... 8

Table 4. Canisters Heat Treatment Schedule ........................................................................ 9

Table 5. Pu Vit Can Glass Monolith to Crack Surface Area Ratios ....................................... 14

Table 6. Can Lengths Pre and Post Heat Treatment ............................................................. 15 


\section{LIST OF ACRONYMS}

ACTL Aiken County Technology Laboratory

CIM Cylindrical Induction Melter

DOE/EM Department of Energy Office of Environmental Management

DWPF Defense Waste Processing Facility

HLW High Level Waste

LaBS Lanthanide Borosilicate (glass)

LAW Low Activity Waste

LMR Linear Melt Rate

MRF Melt Rate Furnace

MST Monosodium Titanate

M\&TE Materials \& Test Equipment

$\mathrm{Pt} / \mathrm{Rh} \quad$ Platinum/Rhodium

PIP Plutonium Immobilization Project

PNNL Pacific Northwest National Laboratory

SMRF Slurry-Fed Melt Rate Furnace

SRNL Savannah River National Laboratory

TSPA Total Systems Performance Assessment

VPWF Vitrified Plutonium Waste Form

WSRC Washington Savannah River Company 


\subsection{INTRODUCTION AND BACKGROUND}

The Department of Energy Office of Environmental Management (DOE/EM) plans to conduct the Plutonium Disposition Project at the Savannah River Site (SRS) to disposition excess weapons-usable plutonium. Vitrification appears to be a viable option for the disposition of the plutonium. An important part of the vitrification approach is to reduce the attractiveness of the plutonium by fabricating a plutonium glass form and immobilizing the plutonium form within the high level waste (HLW) glass prepared in the Defense Waste Processing Facility (DWPF). This requires that the Pu Disposition Project schedule is consistent with EM plans for immobilizing HLW in the DWPF. Therefore, several inputs are needed to provide confidence that the Pu Disposition Project will meet the project schedule. Key inputs are near-term data that will increase confidence that lanthanide borosilicate glass product is suitable for disposal in the Yucca Mountain Repository.

A workshop was held on April 28, 2005 at the Bechtel SAIC Company (BSC) facility in Las Vegas, NV to define the near term data needs. Dissolution rate data and the fate of plutonium oxide and the neutron absorbers during the dissolution process were defined as key data needs. A suite of short-term tests were defined at the workshop to obtain the needed data. The objectives of these short-term tests are to obtain data that can be used to show that the dissolution rate of a LaBS glass is acceptable and to show that the extent of $\mathrm{Pu}$ separation from neutron absorbers, as the glass degrades and dissolves, is not likely to lead to criticality concerns. An additional need to evaluate new frit formulations that may increase the durability of the plutonium glass and/or decrease the degree to which neutron absorbers separate from the plutonium during dissolution was identified. A final data need was identified regarding the degree of macroscopic cracking and/or voiding that occurs during processing of the Pu glass waste form and subsequent pouring of HLW glass in the DWPF.

The surface area that is available for leaching (i.e. due to the degree of cracking or voiding within the Pu glass cylinder) is a factor in modeling the amount of fissile material and neutron absorber released during the dissolution process. A mathematical expression for surface area is used in the Total Systems Performance Assessment (TSPA) performed by BSC personnel. Specifically, the surface area available for leaching is being used in current external criticality assessments. The planned processing steps for producing a Vitrified Plutonium Waste Form (VPWF) assembly involves processing Pu feed and LaBS frit to produce a can of Pu LaBS glass, packaging this can into a second can (i.e. bagless transfer) for removal from the glove box processing environment, placing a series of bagless transfer cans into a DWPF canister, and pouring HLW glass into the DWPF canister to encapsulate bagless transfer cans. The objective of this effort was to quantify the degree of cracking and/or voiding that will occur during the processing of the VPWF. 
The degree of cracking in HLW glass has been extensively evaluated. It was generally concluded that the primary causes of glass fracture in a canister were due to thermal gradients during the pouring and glass cooling cycles and interaction of the glass with the canister (Plodinec, 1989). Handling and movement of the canisters were determined to be a relatively small contributor to fracture unless an impact event occurred (i.e. canister dropping) and even in the event of an impact event the increase in fracture was typically local to the point of impact (Plodinec, 1989).

Testing conducted on large canisters or full-scale DWPF canisters have shown that thermal stresses and glass/canister interactions result in a 7 to 27 times increase in surface area as compared to the monolithic geometric surface area. Pacific Northwest National Laboratory (PNNL) researchers looked at fracturing of glass in $60 \mathrm{~cm}$ diameter carbon steel canisters under conditions of natural convective (air) cooling and slow cooling conditions accomplished through insulating the canisters (Peters, 1981). The results indicated that the air cooled canisters had an increase in surface area up to 27 times while a canister that was insulated to cool 2 to 3 times slower resulted in a smaller 7-fold increase in surface area. Plodinec reported similar results for testing conducted with prototypic DWPF canisters ( $\sim 90 \mathrm{~cm}$ diameter) and concluded that the surface area increase for glass in DWPF canisters could nominally be considered to be 25 times that of the corresponding monolithic canister. Earlier testing conducted at SRS with simulated HLW glass and smaller diameter canisters $(\sim 20 \mathrm{~cm})$ resulted in a surface area increase of 5 times for canisters allowed to air cool (Kessler, 1982).

Based on the reported results for the evaluation of fracturing in HLW glass canisters, Bacon and McGrail (2205) reported surface area increase values for low activity waste (LAW) glass containers for use in the Hanford LAW disposal facility performance assessment (Bacon, 2005). For the LAW container geometry, they specified a surface area increase of 10 times due to fracturing of the glass. 


\subsection{APPROACH}

\subsection{Overview}

This task was executed to determine the degree of cracking and/or voiding that will occur during processing of the VPWF. Prototypic cans of LaBS glass were poured using the Cylindrical Induction Melter (CIM). The cans of glass were exposed to a thermal profile to represent conditions that would be expected during pouring of HLW glass around the Pu glass product cans in the DWPF. The thermal profile utilized in this testing was obtained from testing conducted during the Plutonium Immobilization Project (PIP) to determine the thermal history for pouring of the VPWF assemblies with HLW glass (Smith, 2001). One of the cans subjected to the thermal treatment was loaded into an outer can to simulate the bagless transfer process for removing the $\mathrm{Pu}$ glass product can from the glove box environment. The cans containing the LaBS glass were subjected to non-destructive evaluation (NDE) and destructive analysis techniques to assess the amount of cracking and/or voiding that occurred during processing.

\subsection{Melter System Description}

The Cylindrical Induction Melter (CIM) system installed at the Aiken County Technology Laboratory (ACTL) is a robust and remotely operable system to be used to produce experimental data through vitrification testing. The CIM system is located in the ACTL High Bay. It consists of an inductively heated platinum/rhodium $(\mathrm{Pt} / \mathrm{Rh})$ containment vessel and drain tube, three induction heating systems and power supplies, a Modicon ${ }^{\circledR}$ control system, a chiller, and a simple off-gas venting system (See Figure 1).

Glass forming chemicals are blended and batched to the melter in a carefully measured mass ratio. Volatilization products and other off-gasses are swept into a slotted hood positioned above the top of the CIM vessel, and then drawn through a flexible hose to the laboratory fume hood ventilation system. The glass drains from the bottom of the $\mathrm{Pt} / \mathrm{Rh}$ vessel by gravity through an inductively heated $\mathrm{Pt} / \mathrm{Rh}$ drain tube and into a containment vessel. A separate water chiller provides cooling water to the induction coils, heat stations and power supply cabinets to prevent overheating.

The melter containment vessel is constructed from $80 \%$ platinum / $20 \%$ rhodium alloy, cylindrically shaped, and heats as a result of exposure to changing electro-magnetic fields generated by the heat stations (induction heating). The $\mathrm{Pt} / \mathrm{Rh}$ melter vessel is 14 " high overall, consisting of a 13 " tall by 5 " diameter cylinder, with the lower 1 " tapered to produce a conical transition to the 6" long by 0.20 " I.D. $80 \% \mathrm{Pt} / 20 \% \mathrm{Rh}$ drain tube welded to the bottom (See Appendix 7.1). The vessel wall thickness is 0.080 ", and the drain tube wall thickness is 0.030 ". Four R-type thermocouples are welded to the vessel wall, and a "spring-loaded" contact R-type thermocouple is located to contact the drain tube. A "bed" thermocouple is suspended within the batch bed/glass melt pool from above. The "bed" thermocouple, designated as T6, was Materials $\&$ Test Equipment (M\&TE) calibrated to $+/-10^{\circ} \mathrm{C}$ at $1150^{\circ} \mathrm{C}$. Primary temperature indication for the vessel may be provided by any of the five welded vessel T/Cs, however the T6 bed thermocouple provided the temperature data for the glass product. The vessel is surrounded by a Zircar® insulating cylinder and water-cooled copper coils through which the electric current is passed to produce the electro-magnetic field (see Figure 1). 
Control of the melter vessel, vessel conical bottom, and drain tube temperatures is achieved by making manual power input adjustments to the associated heating stations via the Factory-Link control system. There is no automatic control capability provided for the heating systems.

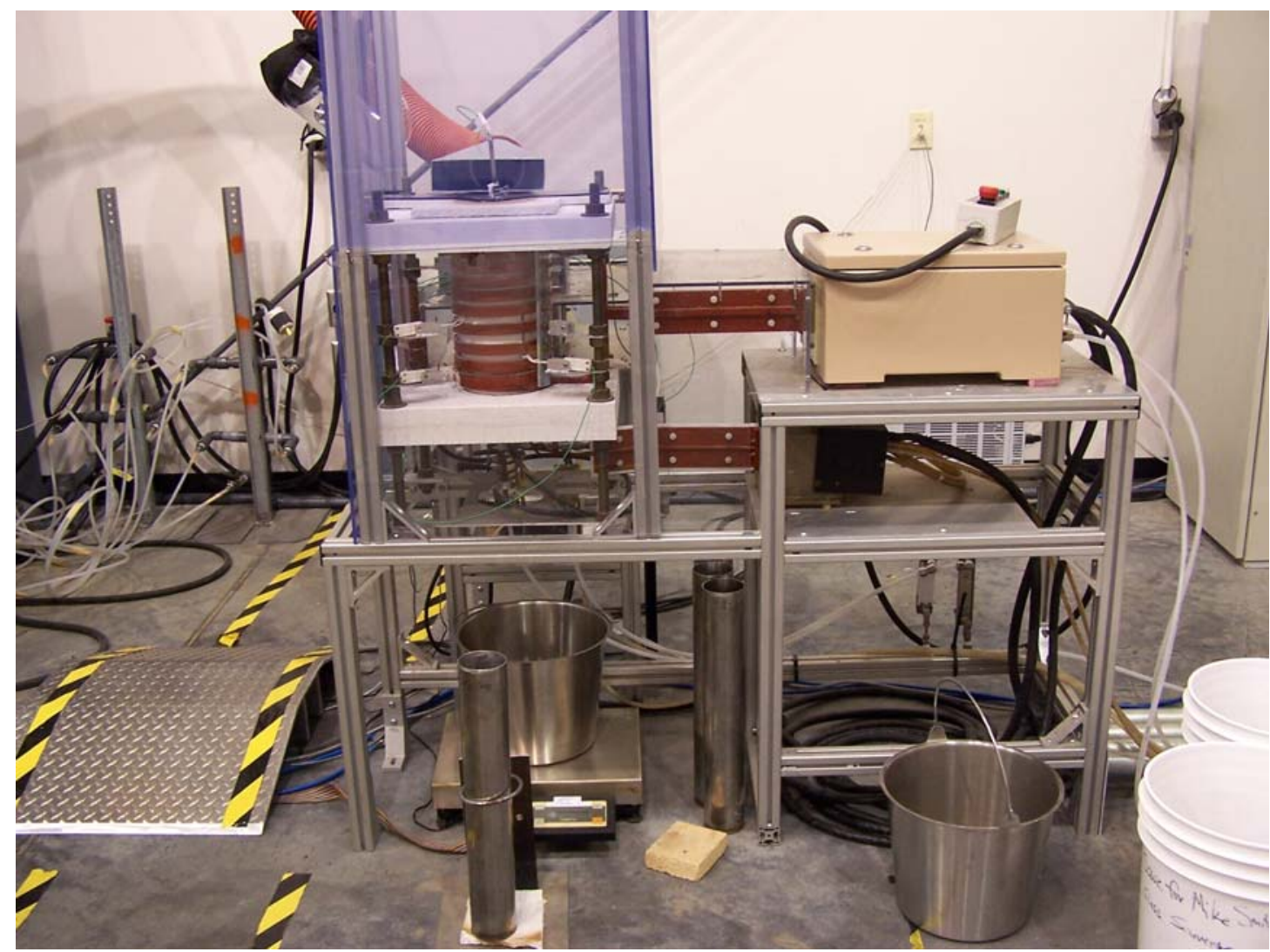

Figure 1. Cylindrical Induction Melter System

\subsection{Prototypic Pu Vitrification Canister Description}

The prototypic canisters that were used for these tests were constructed of 304L stainless steel. Cans of two dimensions were fabricated: the "inner" canister into which the molten glass was poured, and the "outer" canister that represents an enclosure into which the glass-filled "inner" canister is placed for transfer. The "inner" canisters measured 19.25" tall by 2.87 " inside diameter with 0.065 " wall thickness (see Figure 2). The "inner" canisters were filled to within 2 " of the top of the can with LaBS glass during the melter draining operation (see Figure 3 ). The "outer" canisters were constructed of 304L stainless steel, and measured 20.0" tall by 3.25 " inside diameter with 0.125 " wall thickness. The "outer" canisters also had stainless steel caps that loosely fit over the tops of the cans. Liquid penetrant tests were performed per ANSI B31.3 method on the welds of all prototypic "inner" canisters to assure the weld integrity. The design dimensions of the inner and outer canisters are shown in Appendix 7.2. 


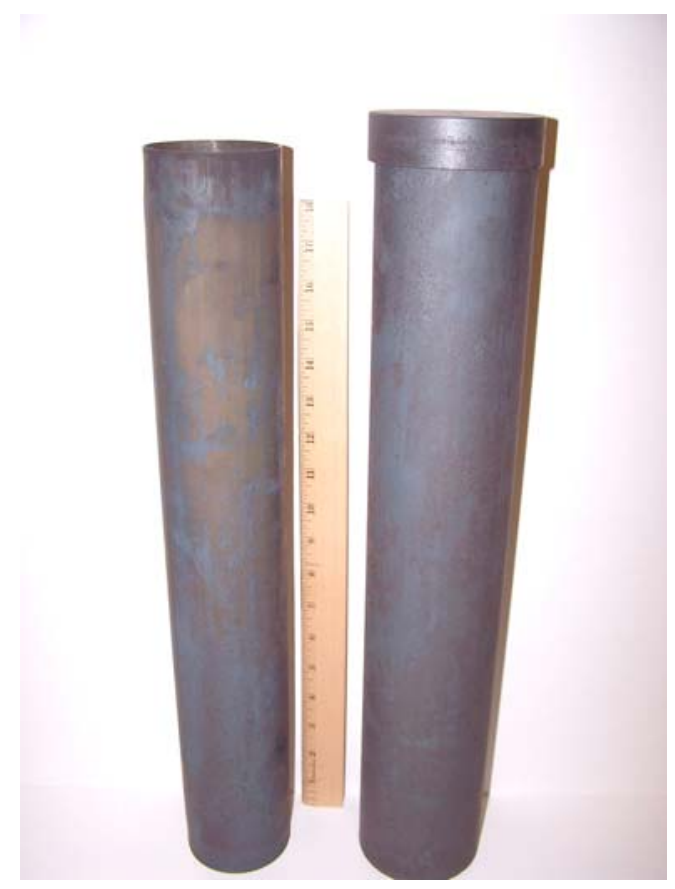

Figure 2. Inner and Outer Cans

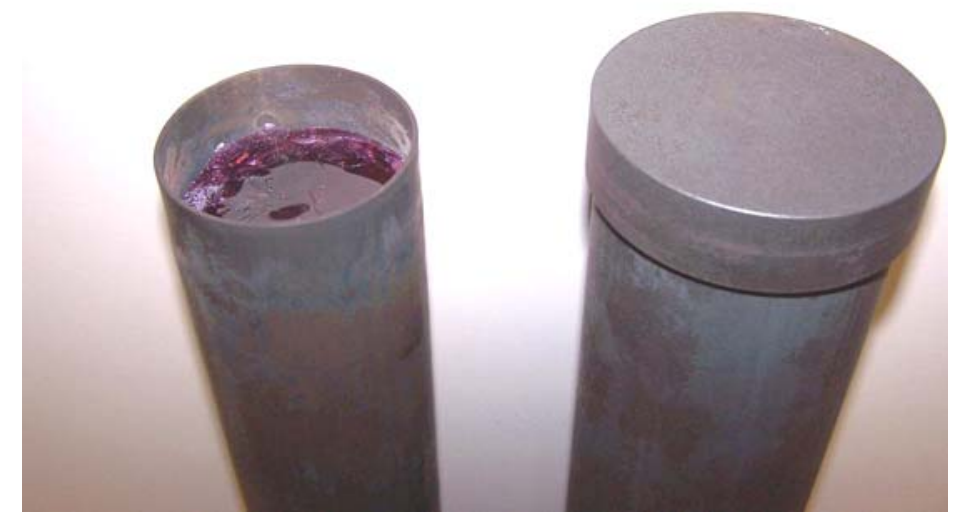

Figure 3. LaBS Glass Filled Inner Can

\subsection{LaBS Glass Preparation}

Initial testing with the Frit $\mathrm{B}$ composition using $\mathrm{HfO}_{2}$ as a surrogate for plutonium indicated issues with hafnium solubility and liquidus temperature. At this point, it was evident that at these high hafnium oxide concentrations, operation of the CIM would be impacted. The use of zirconium oxide as a surrogate for $\mathrm{PuO}_{2}$ was evaluated and determined to be an adequate simulant for the melter testing. Crucible scale tests using $\mathrm{ZrO}_{2}$ added to the glass on an equivalent molar basis to $\mathrm{PuO}_{2}$ resulted in a homogenous glass and melter testing commenced using this composition. During melter testing, however, there were some issues with glass draining from the melter. During one test, the drain tube plugged and it was necessary to remove the plugged section of the drain tube to continue operations. Glass was removed from the drain tube and submitted for analysis. The details of this analysis and the devitrification behavior of the LaBS Frit B glass are detailed elsewhere (Marra, 2006).

The LaBS Frit B glass selected for evaluation in determining surface area was produced in the CIM from feed cullet. The cullet used in the testing was produced by the SRNL vitrification laboratory at ACTL. Two sources of feed materials were used to produce the cullet at ACTL: (1) LaBS Frit B glass batch (from a commercial vendor), vitrified and crushed at ACTL, and (2) batch chemicals blended, vitrified and crushed at ACTL. The compositional analysis for the vendor supplied LaBS Frit B glass batch is shown in Table 1. 
Table 1. LaBS Frit B Batch $\left(\mathrm{Zr}_{2} \mathrm{O}_{3}\right.$ sub for $\left.\mathrm{PuO}_{2}\right)$ From Commercial Vendor

\begin{tabular}{|c|c|c|c|c|c|c|c|c|c|c|}
\hline Sample & $\mathbf{A l}$ & $\mathbf{B}$ & $\mathbf{G d}$ & $\mathbf{H f}$ & $\mathbf{L a}$ & $\mathbf{N d}$ & $\mathbf{S i}$ & $\mathbf{S r}$ & $\mathbf{Z r}$ & \\
\hline \#1 A & 10.6 & 3.05 & 9.75 & 10.4 & 5.68 & 6.27 & 12.5 & $<0.010$ & 2.66 & \\
\hline \#1 B & 10.6 & 2.99 & 9.72 & 10.3 & 5.67 & 6.26 & 12.9 & $<0.010$ & 2.76 & \\
\hline \#2 A & 10.6 & 2.93 & 9.71 & 10.6 & 5.62 & 6.25 & 13.1 & $<0.010$ & 2.83 & \\
\hline \#2 B & 10.3 & 2.87 & 9.69 & 10.5 & 5.64 & 6.28 & 13.0 & $<0.010$ & 2.72 & \\
\hline & & & & & & & & & & \\
\hline & $\mathbf{A l}_{\mathbf{2}} \mathbf{O}_{\mathbf{3}}$ & $\mathbf{B}_{\mathbf{2}} \mathbf{O}_{\mathbf{3}}$ & $\mathbf{G d}_{\mathbf{2}} \mathbf{O}_{\mathbf{3}}$ & $\mathbf{H f O}_{\mathbf{2}}$ & $\mathbf{L a}_{\mathbf{2}} \mathbf{O}_{3}$ & $\mathbf{N d}_{\mathbf{2}} \mathbf{O}_{3}$ & $\mathbf{S i O}_{2}$ & $\mathbf{S r O}$ & $\mathbf{Z r O}_{\mathbf{2}}$ & Total \\
\hline \#1 A & 20.0 & 9.82 & 11.2 & 12.3 & 6.65 & 7.34 & 26.8 & 0.00 & 3.59 & 97.7 \\
\hline \#1 B & 20.0 & 9.63 & 11.2 & 12.2 & 6.63 & 7.32 & 27.6 & 0.00 & 3.73 & 98.3 \\
\hline \#2 A & 20.0 & 9.43 & 11.2 & 12.5 & 6.58 & 7.31 & 28.0 & 0.00 & 3.82 & 98.9 \\
\hline \#2 B & 19.5 & 9.24 & 11.1 & 12.4 & 6.60 & 7.35 & 27.8 & 0.00 & 3.67 & 97.7 \\
\hline
\end{tabular}

Note: Table reflects two samples of Vendor-supplied batch analyzed in duplicate.

In an effort to meet an aggressive time schedule, an attempt was made to obtain the needed LaBS Frit B cullet from a commercial vendor. After weeks of preparation (contract placement, materials acquisition, etc.), the commercial vendor began the process of vitrifying the batch chemicals to make LaBS Frit B cullet. The LaBS glass produced at the vendor's shop aggressively attacked the quartz crucible used by the vendor to contain the melt, eventually penetrating the crucible and spilling onto the vendor's furnace. Two unsuccessful attempts were made by the vendor to produce the LaBS Frit B cullet. The remaining blended batch chemicals were shipped to SRNL, where they were analyzed by the SRNL Mobile Lab for batch composition (see Table 1) and eventually vitrified in Pt/Rh crucibles inside ACTL laboratory furnaces, poured and cooled into patties, and later size-reduced into cullet.

\subsection{Prototype Pu Vitrification Canister Fill}

A run plan was designed to produce a LaBS Frit B glass in the CIM vessel for delivery into a prototypic canister to support the Glass Macrocracking Determination task. The run plan (Jones, 9/12/05) outlined the general steps involved to apply power to the CIM5 vessel, cone and drain tube induction coils to melt LaBS Frit $\mathrm{B}$ cullet. The glass produced was representative of the standard LaBS Frit B glass product, where $\mathrm{ZrO}_{2}$ had been substituted for $\mathrm{PuO}_{2}$.

Five thousand eight hundred grams of LaBS Frit B cullet (final glass $\sim 3.4 \mathrm{~g} / \mathrm{cc}$ ) was charged to the empty CIM5 melter vessel. Then, the vessel and vessel bottom induction heating zones were energized at a low power input to ensure any moisture that may have been present within the cullet was driven off. The vessel and vessel bottom induction coil power inputs were then both ramped to achieve a nominal temperature increase of $10^{\circ} \mathrm{C}$ to $15^{\circ} \mathrm{C}$ per minute at the bed thermocouple, 2T8. When the bed thermocouple reached $1450^{\circ} \mathrm{C}$, an additional 1500 grams of LaBS Frit B cullet was introduced into the hot melter vessel. When the bed thermocouple recovered to $1450^{\circ} \mathrm{C}$, air bubbling through the 7300 grams of glass was initiated at a flow rate of $0.50 \mathrm{scfh}$ to facilitate mixing. The glass melt was targeted to be subjected to air bubbling for 2 hours at $1450^{\circ} \mathrm{C}$, however the glass began draining after only 45 minutes of air bubbling. 
Pouring was allowed to continue, draining the melter contents into a stainless steel prototypic canister identified as Canister \#2. The shorter residence time (45 minutes vs. 2 hours) did not impact the test results.

The drain tube induction coil and most of the $\mathrm{Pt} / \mathrm{Rh}$ drain tube had been removed from the CIM prior to the vitrification run due to pre-existing operational problems (devitrification of glass in the drain tube during initial trials). This devitrification behavior is discussed further in (Marra, 2006). The shorter length (approximately $1 / 2$ inch) of the drain tube was not sufficient to maintain a cold glass plug, which prevents glass draining during normal configuration melter runs.

Prior to initiation of the CIM run to fill Canister \#3, additional cooling air was directed onto the shortened drain tube. The same process was followed to prepare LaBS glass and fill Canister \#3. With additional drain cooling air being applied, the glass melt was mixed by air bubbling at a flow rate of $0.50 \mathrm{scfh}$ for the targeted 2 hours at $1450^{\circ} \mathrm{C}$ prior to pouring initiation.

\subsection{Digital Radiography}

Computed tomography examinations were performed at three locations (bottom, middle, and top) on the two $\mathrm{Pu}$ vitrification canisters. These were done both before and after heat treatment. While adequate for qualitative analysis, the CT examinations suffer from moderate deficiencies and artifacts from lack of penetration due to the high density of the glass material.

Computed Tomography (CT) is the 3-dimensional, volumetric reconstruction of a specimen from 2-dimensional project digital radiographs. The specimen is rotated between the x-ray source and detector while radiographs are acquired at precise intervals over 360 degrees. CT was performed on the Pu Vitrification glass samples using the parameters shown in Table 2.

Table 2. CT Radiographic Setup Parameters

\begin{tabular}{|c|c|}
\hline X-ray generator & Seifert Isovolt HS \\
\hline Voltage & $410 \mathrm{KV}$ \\
\hline Current & $10 \mathrm{~mA}$ \\
\hline Focal Spot & Large \\
\hline \multicolumn{2}{|l|}{ X-ray Filtration } \\
\hline Source & $0.125 " \mathrm{Cu}, 0.032 " \mathrm{~Pb}$ \\
\hline Scintillator & $0.005 " \mathrm{~Pb}$ (initial scan only) \\
\hline Scintillator Type & HD Glass IQI-301 \\
\hline Imager & Roper Scientific Quantix \\
\hline Lense & Nikon 85 mm F1.8 \\
\hline Source-Scintillator Dist & $66.63 ”$ \\
\hline Object-Scintillator Dist & $2.63 "$ \\
\hline Pixel Size & $0.0068^{\prime \prime}$ \\
\hline Angular Range & 360 degrees \\
\hline Images & 480 \\
\hline Angular Increment & 0.75 degrees \\
\hline
\end{tabular}


The canisters were positioned vertically in order to examine a region at the top, middle, and bottom of each. Each can was identically positioned (vertically) in both pre and post inspections (see Table 3 and Appendix 7.4). The rotational positions of the pre-heat treated cans were not controlled, and alignment was accomplished by rotating and shifting the post-heat treated data sets using individual porosity as alignment markers.

The digital radiographs were processed to horizontal slices using the Feldkamp cone-beam reconstruction algorithm as implemented by Lawrence Livermore National Laboratory software code. The CT slices in their raw form were processed using a 3-dimensional smooth filter to increase feature distinction. Individual slices were processed by a high pass-filter to attenuate the bulk material and amplify the appearance of any inconsistencies and discontinuities in the materials (e.g. porosity, voids, or cracking). The slices were then assembled into a 3-d data set using in-house software. To allow for detailed observation of the can distortion experienced during annealing, a data set was generated by geometrically "unwrapping" each slice from around its center point as diagrammed (see Figure 4).
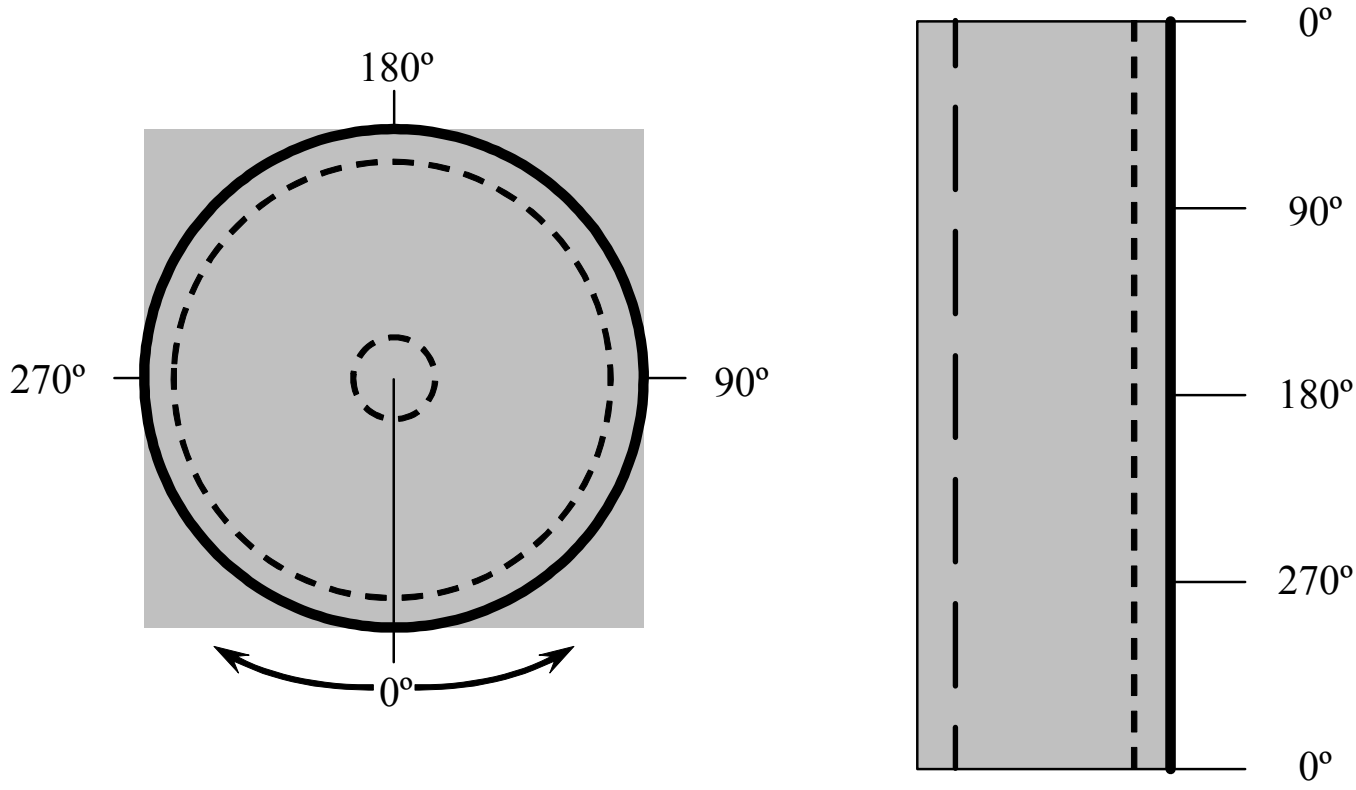

Figure 4. Radial Slice Construction

While distorting the central region, it allows for better display and understanding of the edge region geometry. These radial slices can also be stacked together and displayed as a vertical slice image.

Table 3. Examined Can Sections

\begin{tabular}{|l|l|l|l|}
\hline Region & Lower Bound & Upper Bound & Height \\
\hline Bottom & $0.00 "$ & $4.12 "$ & $4.12{ }^{\prime}$ \\
\hline Middle & $6.07 "$ & $10.62 "$ & $4.55 "$ \\
\hline Top & $14.51 "$ & $19.06 "$ & $4.55 "$ \\
\hline
\end{tabular}




\subsection{Canisters Heat Treatment}

The two prototype canisters filled with LaBS Frit B glass were heat treated in an annealing furnace to simulate the conditions they would be exposed to inside a DWPF canister during a standard operation of filling with DWPF waste glass. Previous tests were conducted where a standard DWPF canister fitted with can-in-canister hardware was instrumented with thermocouples to measure the temperature at various locations during glass filling (See Figure 7). The tests are documented in the "Phase 2 Can-In-Canister Cold Pour Tests for the Plutonium Immobilization Project" report, WSRC-TR-2000-00408. Data provided by thermocouple T7.3 (welded to CIC can), which was located at the 84" glass height and positioned 6.3" from the centerline of the DWPF test canister, served to provide the targeted profile for the prototype canisters heat treatment (See Figure 6). This was the most extreme temperature experienced by any measured canister position.

Based on the previous can-in-canister testing, the test cycle time for this task was reduced by ramping as follows:

Table 4. Canisters Heat Treatment Schedule

\begin{tabular}{|l|l|l|l|}
\hline Step 1 & Heat 5 Hrs & 25 C to 500 C & Ramp at 100C/Hr \\
\hline Step 2 & Heat 2 Hrs & 500C to 900C & Ramp at 200C/Hr \\
\hline Step 3 & Soak $1 / 2 \mathrm{Hr}$ & 900C & Hold 30 minutes \\
\hline Step 4 & Cool 2 Hrs & 900C to $840 \mathrm{C}$ & Ramp down at 30C/Hr \\
\hline Step 5 & Cool 2 Hrs & 840C to 700C & Ramp down at 70C/Hr \\
\hline Step 6 & Cool 13 Hrs & 700C to 320C & Ramp down at 30C/Hr \\
\hline Step 7 & Cool 4 Hrs & 320C to 240C & Ramp down at 20C/Hr \\
\hline Step 8 & OFF & & \\
\hline
\end{tabular}

Total Heat Cycle Time $=28.5$ Hrs

The quartz annealing furnace, located at the SRNL Glass Apparatus Fabrication Shop, was selected for the prototype canisters' heat treatment. Due to the limited height of the furnace (19inches tall), the canisters had to be laid horizontally (on their sides) inside the furnace. Canister \#3 was placed inside an outer canister and cover cap to mimic the bagless transfer process. A thermocouple (T1C) was placed within the void space at the top of Canister \#3, within the outer canister. Canister \#2 was placed inside the furnace "as is", without any additional covering. A control thermocouple (T2C) was placed between the two canisters inside the annealing furnace.

The entire glass filling (heating) and cool down of the cans in the DWPF test required $42+$ hours (See Figure 5). The heat treatment schedule for this test was reduced by eliminating the time taken for the glass to reach the T7.3 thermocouple at the 84" height in the DWPF canister, i.e. $42+$ hours for can-in-canister test reduced to 28.5 hours for this heat treatment cycle.

The T2C thermocouple became erratic during the cooling phase of the test. Post testing calibration check of the thermocouple indicated the thermocouple to be functioning properly. It is believed a cold junction of the thermocouple leads was experienced during the test, resulting in the erratic temperature indication for $\mathrm{T} 2 \mathrm{C}$. The actual furnace temperature did not fluctuate from its programmed schedule. 


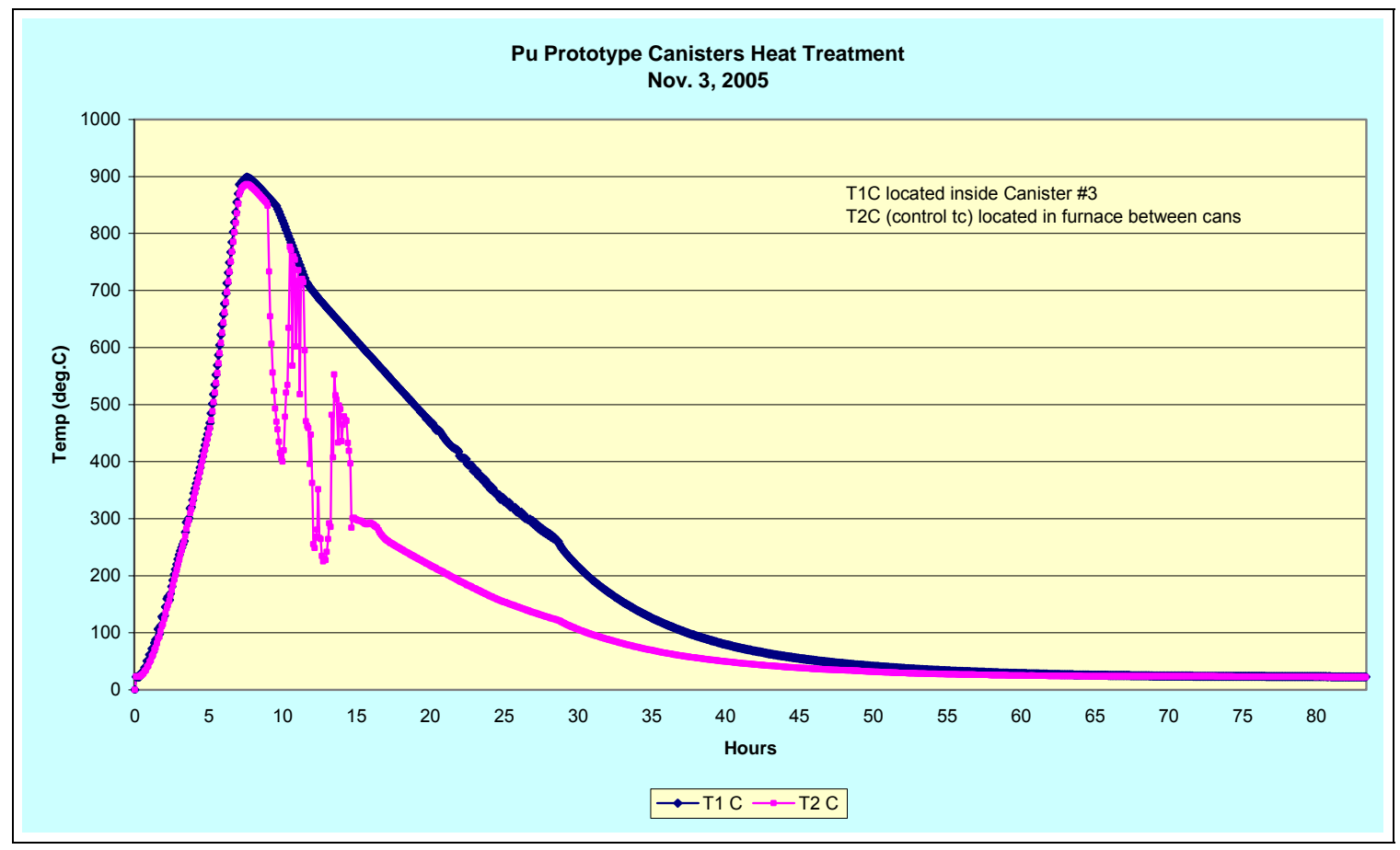

Figure 5. Prototype Canisters Heat Treatment

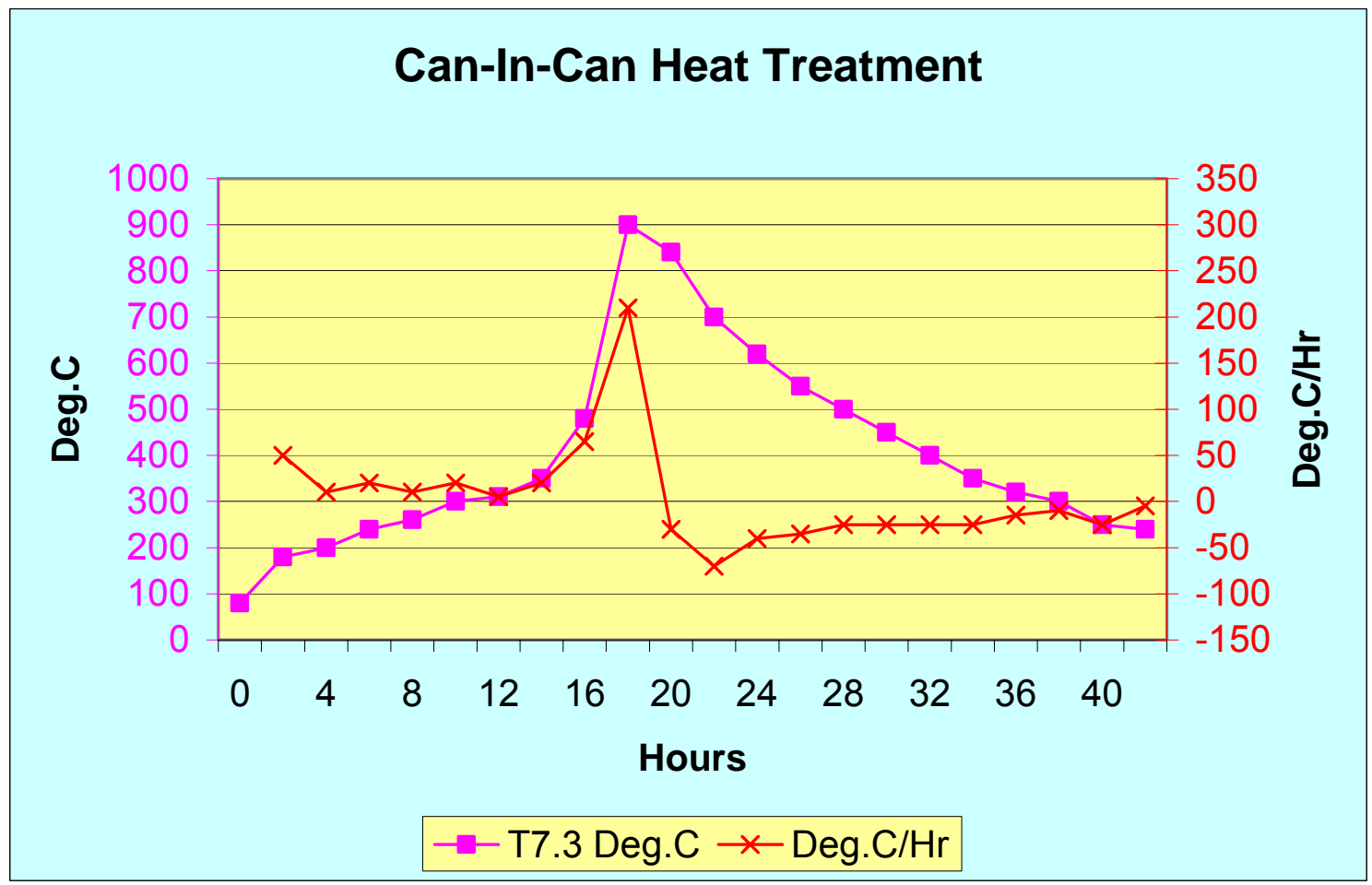

Figure 6. Phase 2 Can-In-Canister Cold Pour Tests 


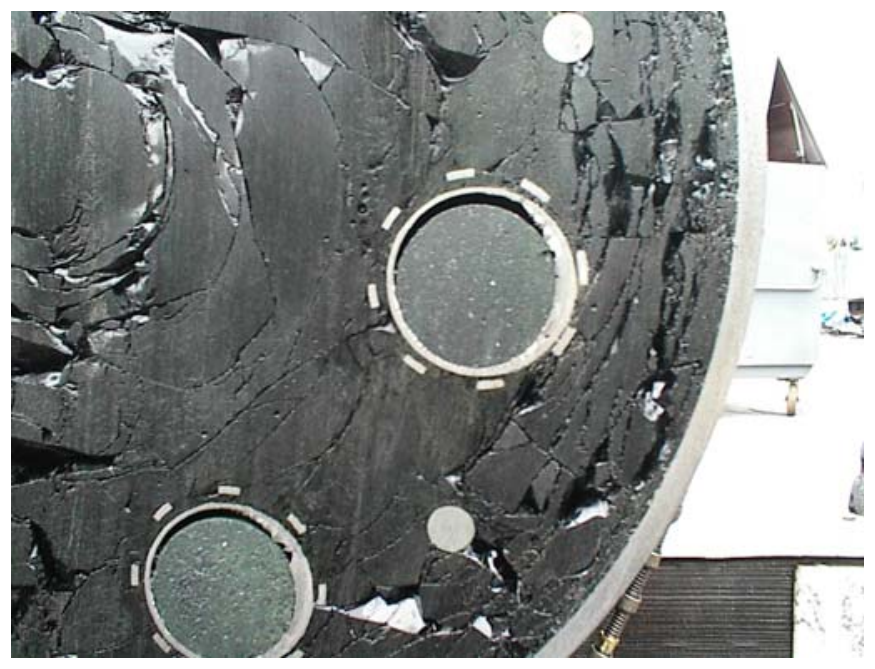

Figure 7. Sectioned DWPF-type Canister

\subsection{Prototype Canisters Sectioning}

The LaBS Frit B glass-filled prototypical canisters were sectioned following completion of the post-heat treatment digital radiography analysis. The SRNL Glass Shop used a water-cooled aluminum oxide cutting wheel to section the 304 series stainless steel canisters. Then a watercooled Carborundum ${ }^{\mathrm{TM}}$ cutting wheel was used to section the LaBS glass inside the cans.

Canister \#2 was section by three cuts (see Figure 8), yielding the top surface section (33 mm glass thickness), the upper cut section (194 mm glass thickness), the mid-section (212 mm glass thickness), and the bottom section (26 mm glass thickness). See Appendix 7.3 for illustration of sectioned canister dimensions. Canister \#3 was section by four cuts (See Figure 9), yielding the top surface section (32 mm glass thickness), the upper cut section (201 mm glass thickness), the mid-section (180 mm glass thickness), the lower section (22 $\mathrm{mm}$ glass thickness), and the bottom section (25 mm glass thickness). The lower section of canister \#3 was not used in determining surface area increase due to cracking, so that only four sectioned samples were considered for each canister.

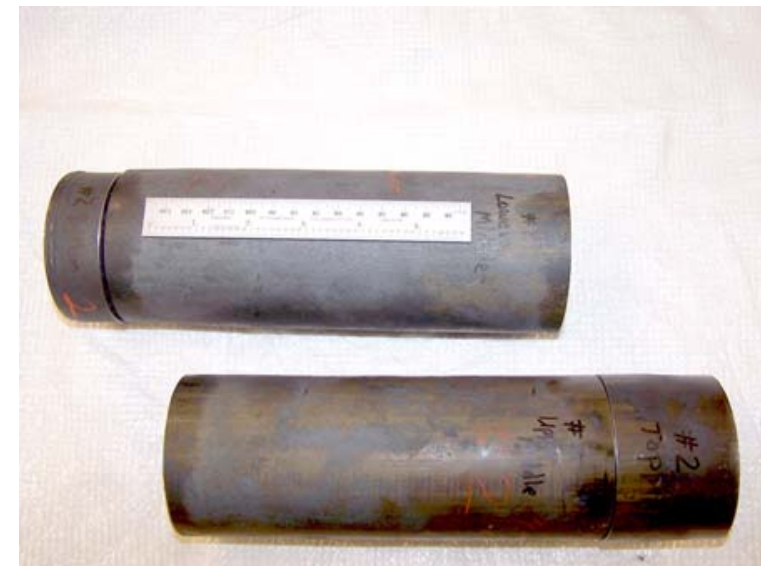

Figure 8. Sectioned Canister \#2

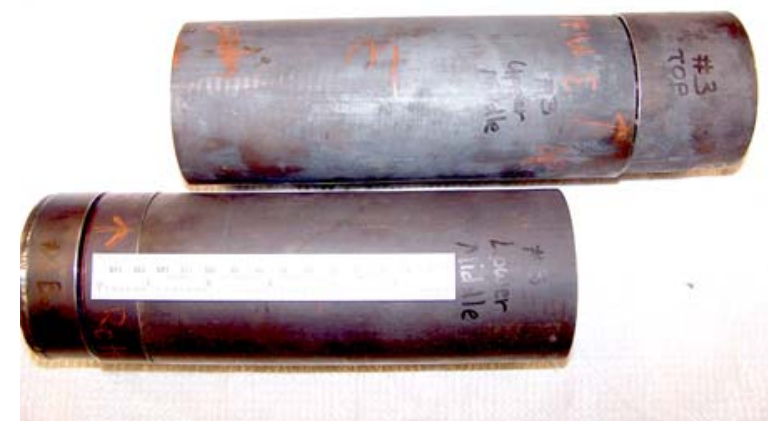

Figure 9. Sectioned Canister \#3 


\subsection{Macroscopic Crack Determination}

Digital radiography was employed to analyze the canisters prior to heat treatment in an attempt to determine a baseline for cracks and voids in the glass monoliths resulting from the initial canister filling with the molten LaBS glass. However, the relatively high atomic masses of the elements in the lanthanide borosilicate glass precluded the production of useful images by the radiographic methods. Following heat treatment, the canisters were again analyzed by digital radiography to determine what, if any, changes occurred within the glass monolith. Although radiography information will not be conclusive (due to the elements of the LaBS glass discussed above), there were slight changes in the glass monoliths with respect to the sizes and locations of some of the voids following the heat treatment and cooling process. Since the radiography was unable to yield conclusive data for measuring the lengths of the cracks in the glass monoliths, information resulting from the radiography will only be used for comparative purposes.

The canister sections were visually analyzed to determine the presence and length of fractures within the glass monoliths. Four sections from each canister were photographed. The photograph prints were examined, the crack lengths measured to scale shown on the individual photographs, and recorded (See Figure 10 thru Figure 17). The crack lengths were summed for each section and compared to the geometric surface area of the slice. The ratio of these measurements provided a measure of the relative increase in surface area.

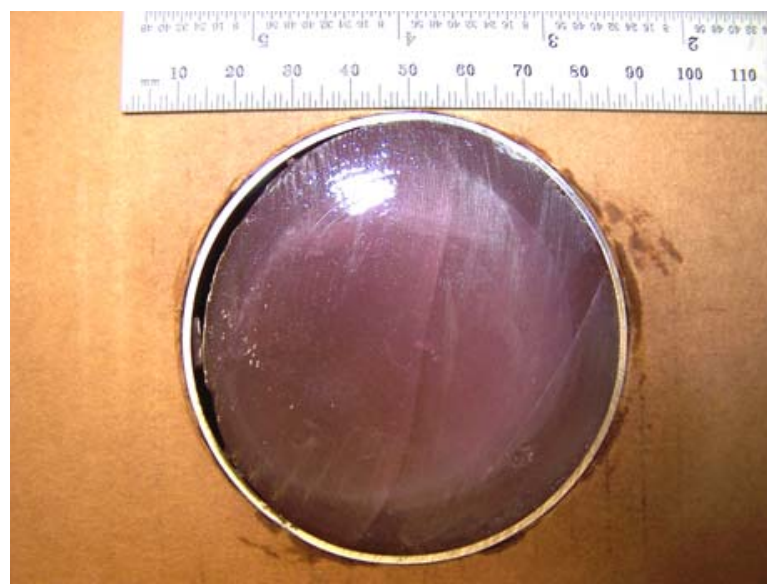

Figure 10. Sectioned Canister \#2 Bottom

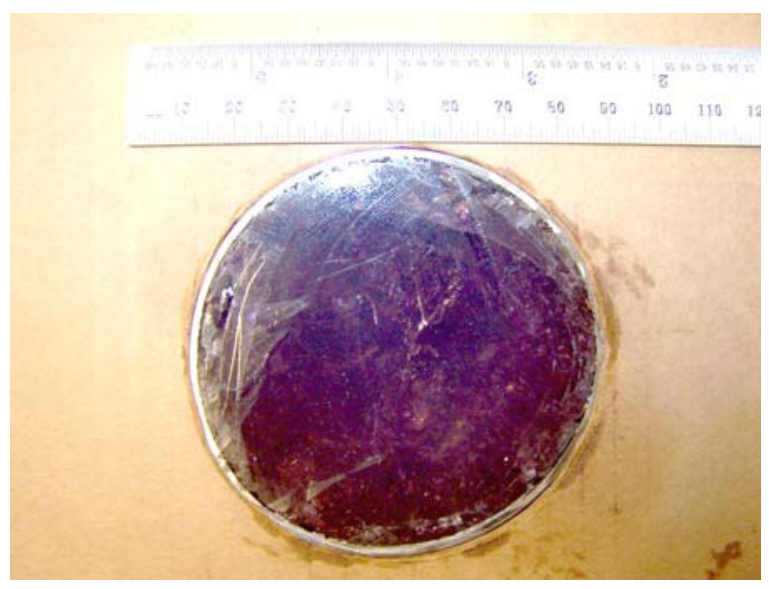

Figure 11. Canister \#2 Mid Section Cut 


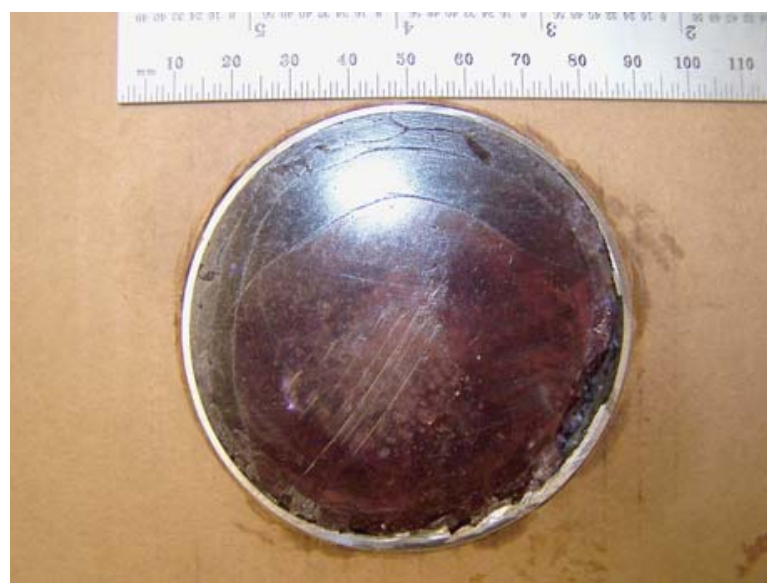

Figure 12. Canister \#2 Upper Cut

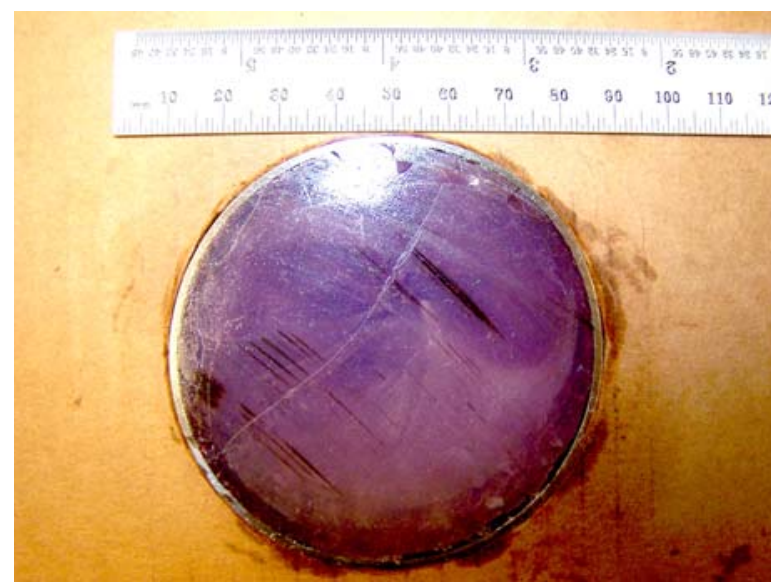

Figure 14. Sectioned Canister \#3 Bottom

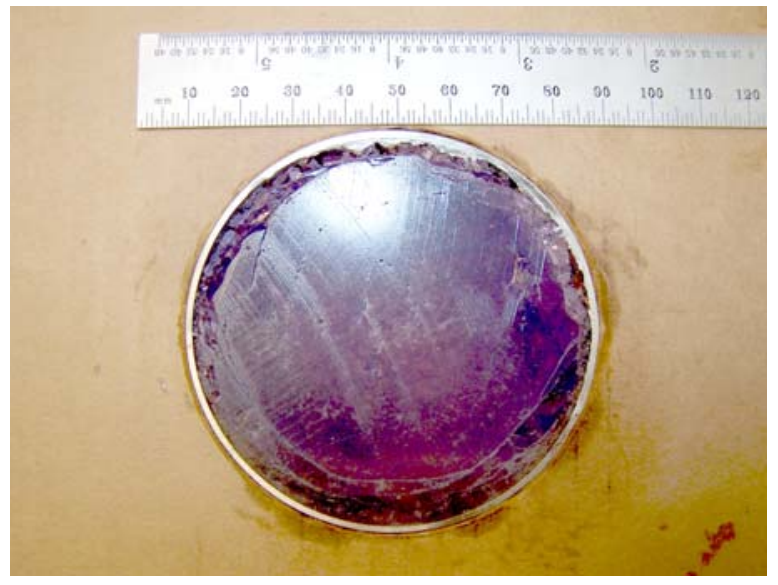

Figure 16. Canister \#3 Upper Cut

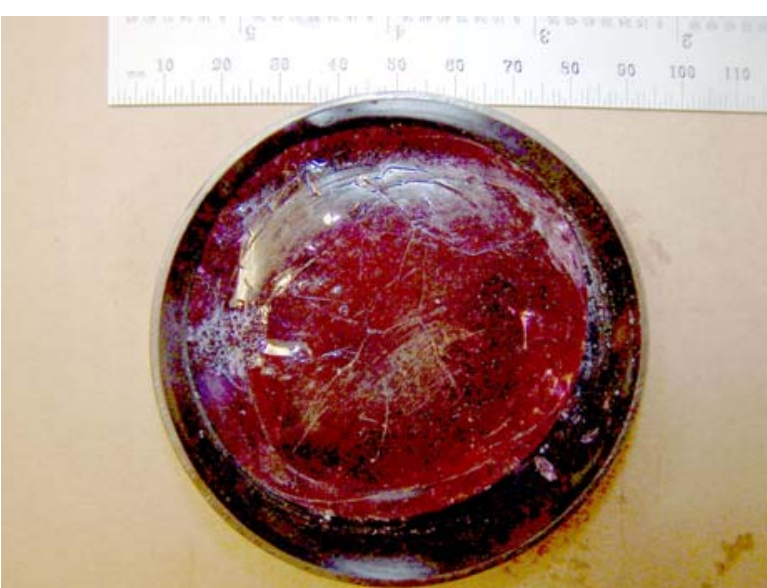

Figure 13. Canister \#2 Top Surface

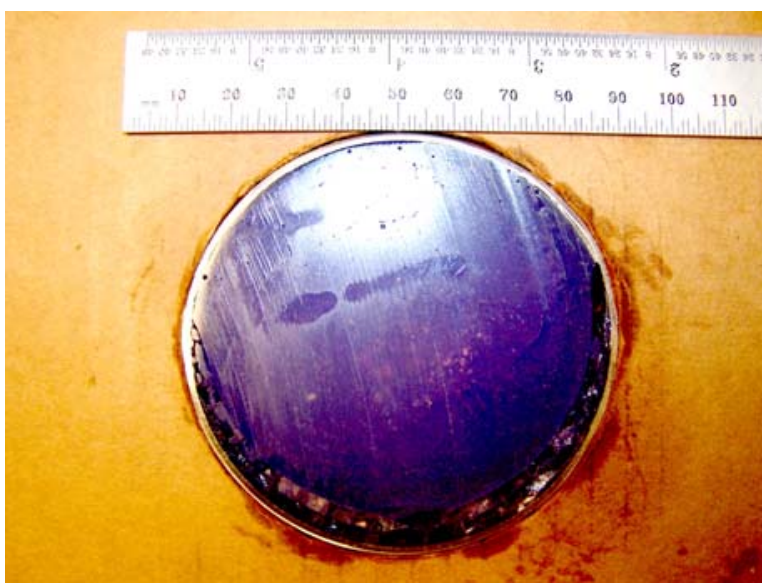

Figure 15. Canister \#3 Mid Section Cut

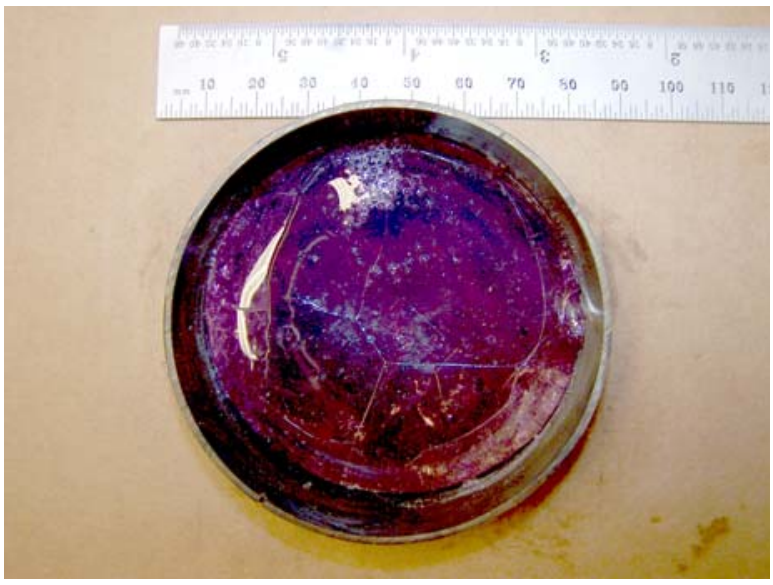

Figure 17. Canister \#3 Top Surface 


\subsection{RESULTS}

\subsection{Macrocracking Surface Area Determination}

Testing conducted on large canisters or full-scale DWPF canisters have shown that thermal stresses and glass/canister interactions resulted in a 7 to 27 times increase in surface area as compared to the monolithic geometric surface area (Peters, 1981). Earlier testing conducted at SRS with simulated HLW glass and smaller diameter canisters $(\sim 20 \mathrm{~cm})$ resulted in a surface area increase of 5 times for canisters allowed to air cool (Kessler, 1982).

Testing conducted under this task on stainless steel canisters of 2.87 inch inside diameter indicated thermal stresses and glass/canister interactions result in a 1.8 to 4.1 times increase in surface area due to glass cracking (see Table 5). The canisters were filled with LaBS Frit B glass with $\left(\mathrm{ZrO}_{2}\right.$ substituted for $\left.\mathrm{Pu}\right)$ processed at $1450^{\circ} \mathrm{C}$ and allowed to cool. The cooling of the glass-filled canisters was not influenced by any external factors, such as insulating the cans or applying additional cooling forces such as air drafts, etc. The canisters were next subjected to heat treatment inside a furnace to simulate exposure to temperatures within a standard DWPF canister during glass filling and cool down. Can \#3 was heat treated while inside an outer containment canister to simulate a bagless transfer container configuration. Can \#2 was heat treated in its natural condition, i.e. not within additional containment.

Table 5. Pu Vit Can Glass Monolith to Crack Surface Area Ratios

\begin{tabular}{|c|c|c|c|c|c|c|}
\hline Can \# & Section & $\begin{array}{c}\text { SA - } \\
\text { Monolith } \\
\text { Surface } \\
\text { Area } \\
\left.\mathbf{( m m}^{\mathbf{2}}\right)\end{array}$ & $\begin{array}{c}\text { Ht. - } \\
\text { Section } \\
\text { Height } \\
\mathbf{( m m )}\end{array}$ & $\begin{array}{c}\text { L - } \\
\text { Crack } \\
\text { Length } \\
\mathbf{( m m )}\end{array}$ & $\begin{array}{c}\text { CSA - } \\
\text { Crack } \\
\text { Surface } \\
\text { Area } \\
\mathbf{m m}^{\mathbf{2}} \mathbf{)}\end{array}$ & $\begin{array}{c}\text { CSA+SA / SA } \\
\text { Increase in } \\
\text { surface area }\end{array}$ \\
\hline $\mathbf{2}$ & Top & 15,905 & 33 & 505.5 & 33,363 & $\mathbf{3 . 1}$ \\
\hline $\mathbf{2}$ & Upper Cut & 52,778 & 194 & 379.5 & 147,246 & $\mathbf{3 . 8}$ \\
\hline $\mathbf{2}$ & Mid-section & 56,900 & 212 & 401.5 & 170,236 & $\mathbf{4 . 0}$ \\
\hline $\mathbf{2}$ & Bottom & 14,303 & 26 & 245.75 & 12,779 & $\mathbf{1 . 9}$ \\
\hline & & & & & & \\
\hline $\mathbf{3}$ & Top & 15,676 & 32 & 349.5 & 22,368 & $\mathbf{2 . 4}$ \\
\hline $\mathbf{3}$ & Upper Cut & 54,381 & 201 & 419.5 & 168,639 & $\mathbf{4 . 1}$ \\
\hline $\mathbf{3}$ & Mid-section & 49,572 & 180 & 166 & 59,760 & $\mathbf{2 . 2}$ \\
\hline $\mathbf{3}$ & Bottom & 14,074 & 25 & 249 & 12,450 & $\mathbf{1 . 9}$ \\
\hline
\end{tabular}

Where:

$\mathrm{D}=$ can inside diameter $=72.9 \mathrm{~mm}$

$\mathrm{L}=$ crack length

Ht. $=$ can section height $(\mathrm{mm})$

$\mathrm{CSA}=$ crack surface area $=2 \mathrm{~L} \times \mathrm{Ht}$

$\mathrm{r}=$ can inside radius $=36.45 \mathrm{~mm}$

$\mathrm{A}=\mathrm{x}$-sectional area $=\pi \mathrm{r}^{2}=\pi(36.45 \mathrm{~mm})^{2}=4,173.9 \mathrm{~mm}^{2}$

$\mathrm{C}=$ circumference $=2 \pi \mathrm{r}=2 \pi(36.45 \mathrm{~mm})=229.02 \mathrm{~mm}$

$\mathrm{SA}=$ surface area $=(\mathrm{C} \times \mathrm{Ht})+.2 \mathrm{~A}$ 
It was evident that heat treatment of the can in the outer canister had no discernable effect on the degree of glass cracking when compared to the can that was heat treated "as is". The assumption that the cracks observed at the cross sections of the canister cuts extend through the entire length of the can section results in a highly conservative estimate of increased surface from glass cracking.

\subsection{Digital Radiography Tomography Results}

The glass-filled canisters were inspected using digital radiography/computed tomography (CT) with qualified results. The $\mathrm{CT}$ images suffered from moderate artifacts and degradation due to the thickness and high density of the glass material. Figure 18 and Figure 19 show sectional slices of the cans after heat treatment. Figure 20 explains the radial slice images used to evaluate the degree of cracking and presence of voids (porosity) within the glass, as well as the method for evaluating the deformation of the canisters as a result of the heat treatment process.

Figure 21 - Figure 35 show these radial slice images.

\subsubsection{Porosity}

Both cans show a small amount of porosity. The porosity is generally distributed near the canister wall over the entire length of material. Both samples show porosity in the center of the can in the top section. Comparing the pre- and post-heat treated scans shows that the number and size of the pores in the glass decreased during the heat treatment. Figure 22 shows Canister \#2 composite CT generated radiographs $\left(0^{\circ}\right.$ and $90^{\circ}$ views $)$ of pre-heat treated and post-heat treated top, middle and bottom sections. Vertical slices of the top, middle and bottom sections of Canister \#2 are shown in Figure 26, Figure 27 and Figure 28. Figure 29 shows composite CT generated radiographs $\left(0^{\circ}\right.$ and $90^{\circ}$ views $)$ of Canister $\# 3$ pre-heat treated and post-heat treated top, middle and bottom sections. Vertical slices of the top, middle and bottom sections of Canister \#3 are shown in Figure 33, Figure 34 and Figure 35.

\subsubsection{Deformation}

Geometric analysis of post-heat treated cans revealed a deformation of the can and glass material. Both cans were deformed from a circle into an eccentric oval shape. The can radius is deflected outward in two locations and inward between these two nodes. Canister \#3 is more deformed than Canister \# 2. The deformation in Canister \#2 can be seen in section CT slices shown in Figure 23, Figure 24 and Figure 25. The deformation in Canister \#3 can be seen in section CT slices shown in Figure 30, Figure 31 and Figure 32.

In both samples, the glass is higher in the post-heat treatment inspection by approximately 0.2 " (see Table 6). In the pre-heat treated scan the glass completely fills the can and, except for a small annulus at the bottom of the can, in complete contact with the inner can wall. In the postheat treatment inspection the glass has separated from the can wall corresponding to the arc of outward deformation.

Table 6. Can Lengths Pre and Post Heat Treatment

\begin{tabular}{|c|c|c|c|}
\hline & \multicolumn{2}{|c|}{ Scan } & \\
\hline Can \# & Pre & Post & Difference \\
\hline 2 & $18.44 ”$ & $18.64 "$ & $+0.20 "$ \\
\hline 3 & $18.57 ”$ & $18.74 ”$ & $+0.17 ”$ \\
\hline
\end{tabular}




\subsubsection{Cracking}

The capability of radiography to detect cracks is limited. Compressed fractures, where there is no separation of material, have a low probability of detection. Open cracks, where the sides of the material are not in contact, are more readily detected. Further hindering complete crack detection is the high density of the material itself. While complete quantification of the amount of cracking is not possible, qualitative analysis of the observe cracks is useful. There were major changes in the amount of cracking between the pre and post-heat treated inspections. Except for a minor crack in the bottom heel of Can 2, there was no observable cracking in either of the preheat treated glass samples.

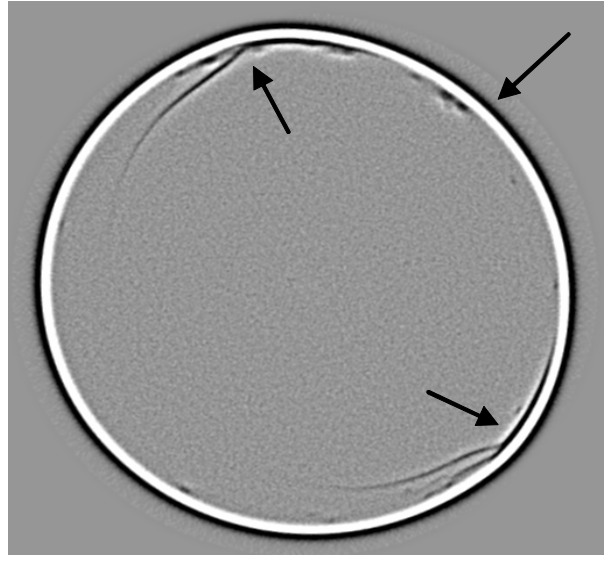

Figure shows:

- typical can deformation of two outward and one inward distortions

- $\quad$ arc cracking emanating from the outward nodes

- wall porosity location and size

- glass separation from the can at outward deformation nodes.

Figure 18. Post-Heat Treated CT slice from Canister \#2 Middle Section

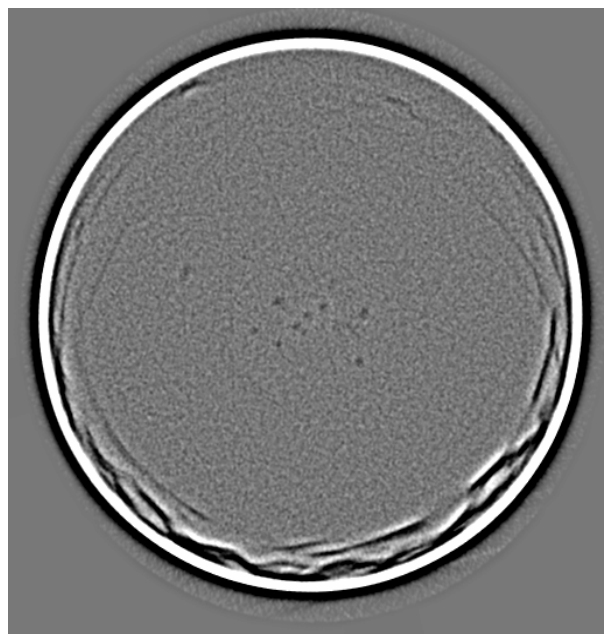

Figure shows:

- chaotic cracking in the outer edge of glass

- central porosity location and size

- reduced deformation at extremities of the can

Figure 19. Post-Heat Treated CT slice from Canister \#3 Top Section 
Post heat treated inspections show three types of cracks in the material (arc, chaotic, and horizontal). Both samples have vertical arc shaped cracks emanating from the two deformation nodes running the length of the material. The magnitude of the arc cracks is proportional to the magnitude of the can deformation, appearing and intensifying through the bottom section, large and constant in the middle section, and abating through the top section.

Observable in both samples in the top section is a chaotic fracturing of the glass in the arc corresponding to the inward deformation. The extent of chaotic fracturing is larger in Canister \#2. Canister \#3 shows a large horizontal crack in the lower middle section. 
Post-annealed Scan CT generated radiograph of Top, Middle, and Bottom annealed section

Radial Slices from Preannealed section

Marker lines showing approximate slice location

Pre-annealed Scan CT generated radiograph of, Top, Middle, and Bottom

Graph showing radial distance from slice center point to the can outer surface. "Ref" line is from center pre-annealed slice.

Figure 20. Radial Slice Image Explanation 


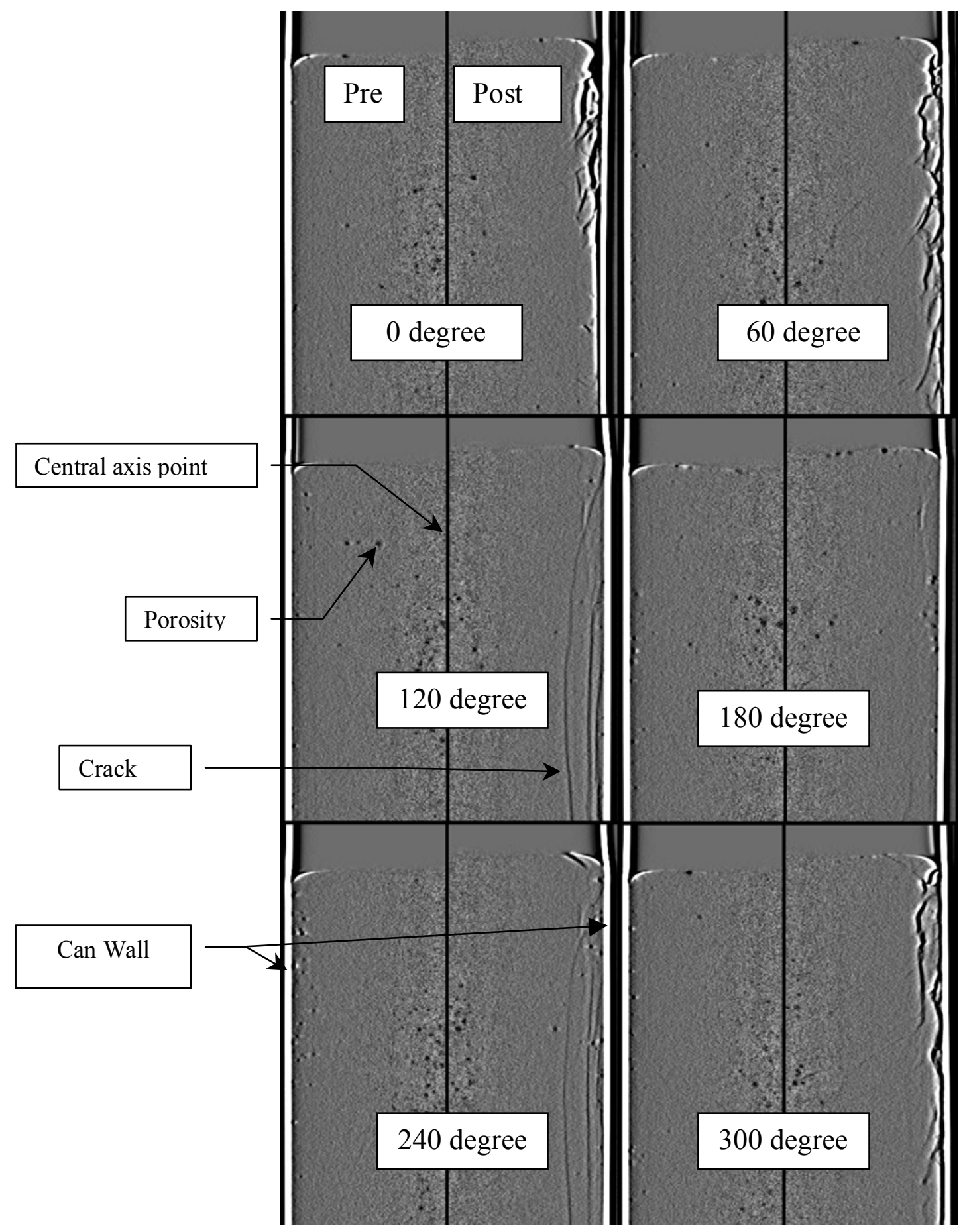

A vertical slice created by assembling data points at a constant angle $(0,60$, $120,180,240$, and 300) radiating from the center point from horizontal slices. The pre-anneal scan is flipped horizontally and abutted to the postanneal scan. Each side (Pre and Post) displays the same view from each scan and can be directly compared.

Figure 21. Pre-heat treated and Post-heat treated Canister CT Scans 

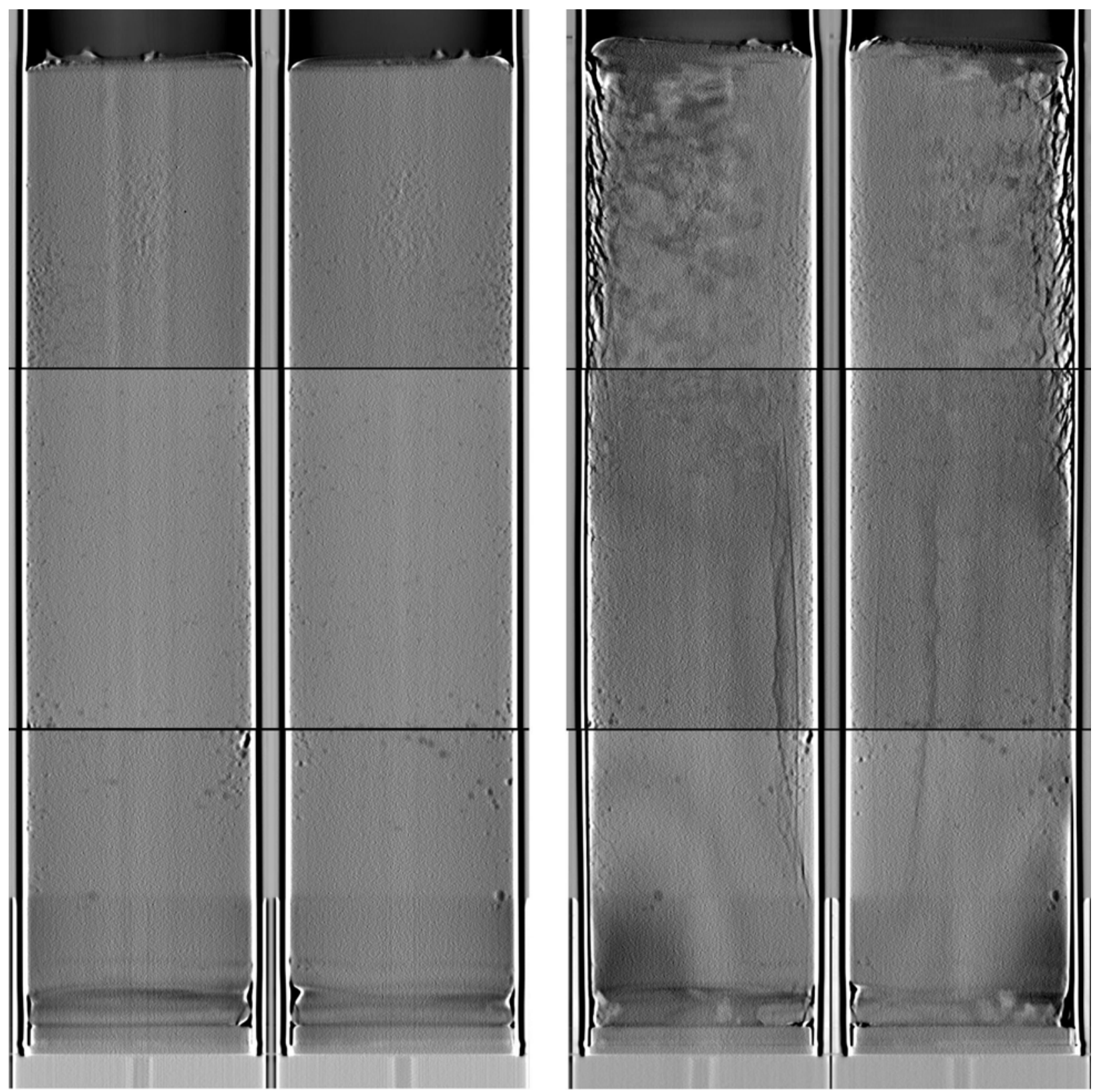

Figure 22. Canister \#2 Composite CT Generated Radiographs

Can 2 composite CT generated radiographs 0 and 90 degrees views of pre-annealed (left) and post-annealed (right) top, middle and bottom sections. 
WSRC-TR-2006-00015

Revision 0
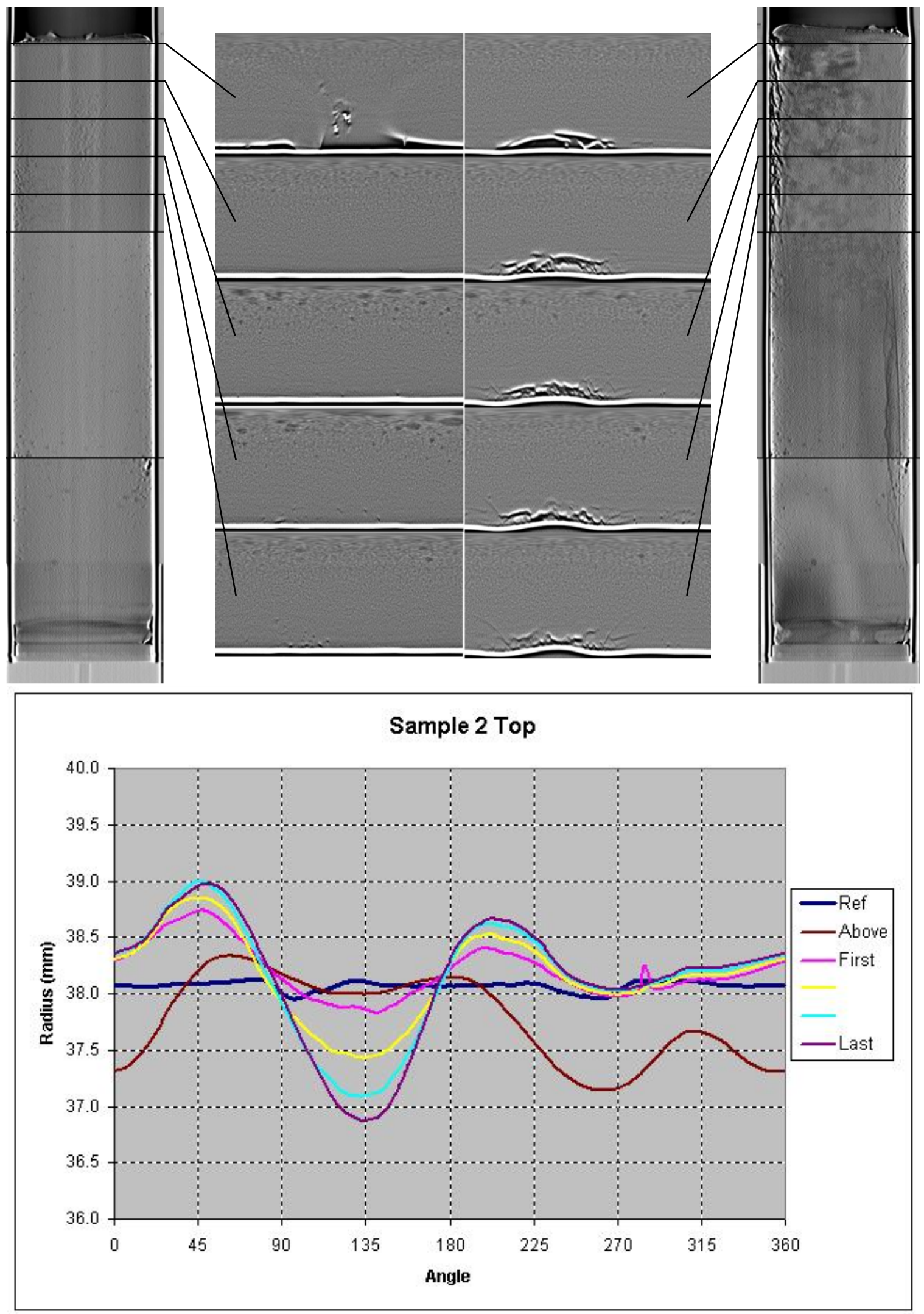

Figure 23. Canister \#2 Top Section CT Slices 
WSRC-TR-2006-00015

Revision 0
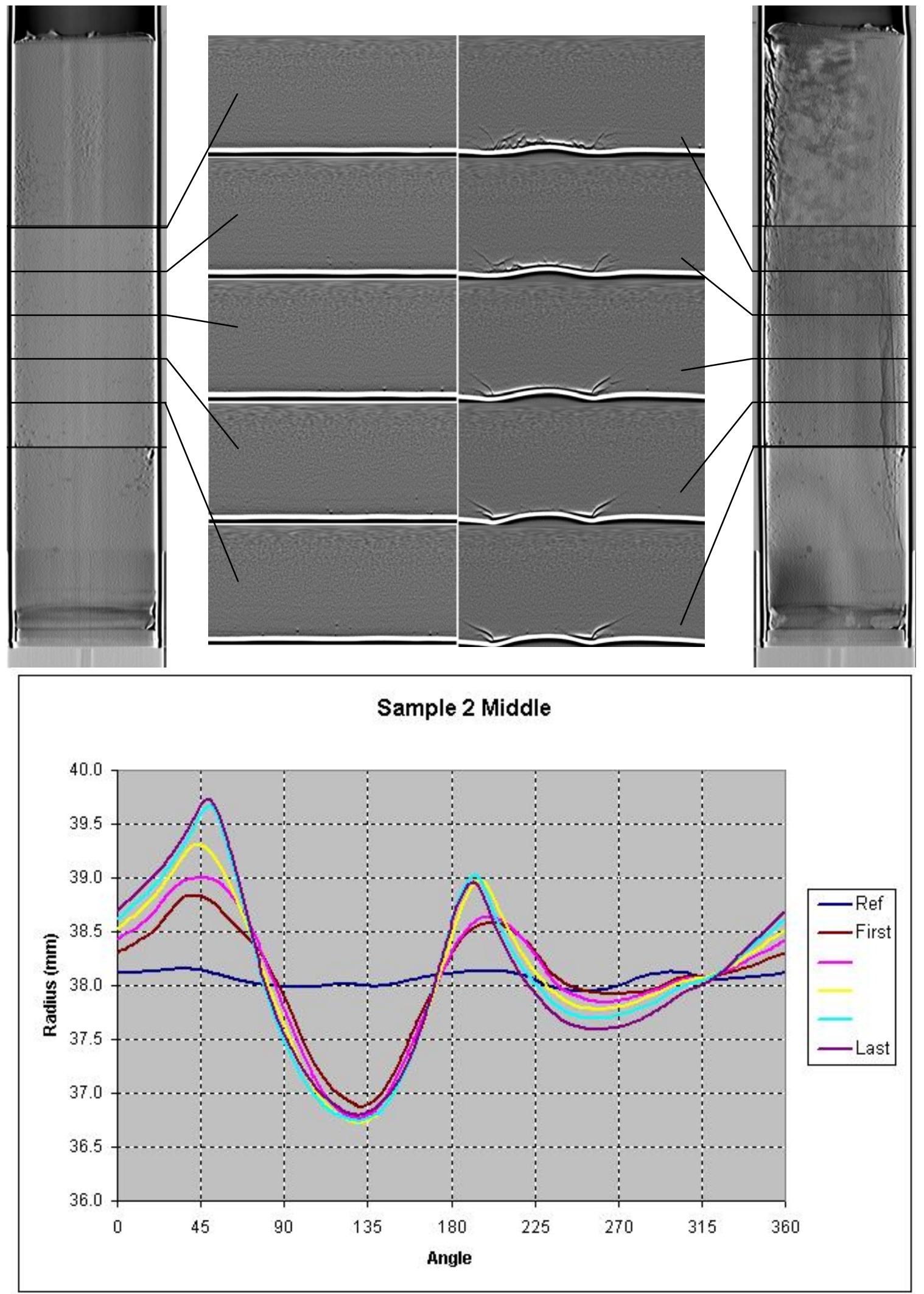

Figure 24. Canister \#2 Middle Section CT Slices 
WSRC-TR-2006-00015

Revision 0
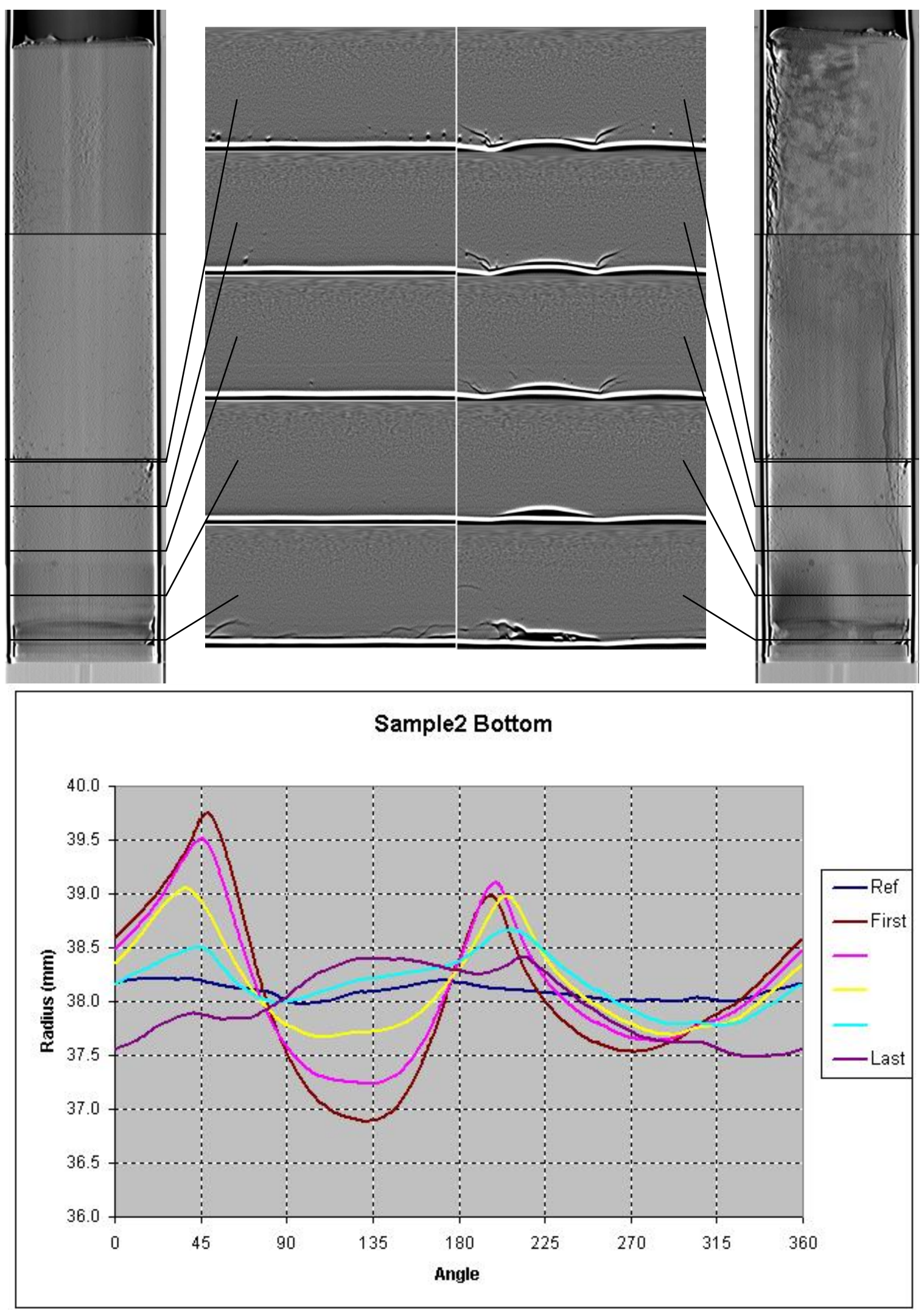

Figure 25. Canister \#2 Bottom Section CT Slices 
WSRC-TR-2006-00015

Revision 0

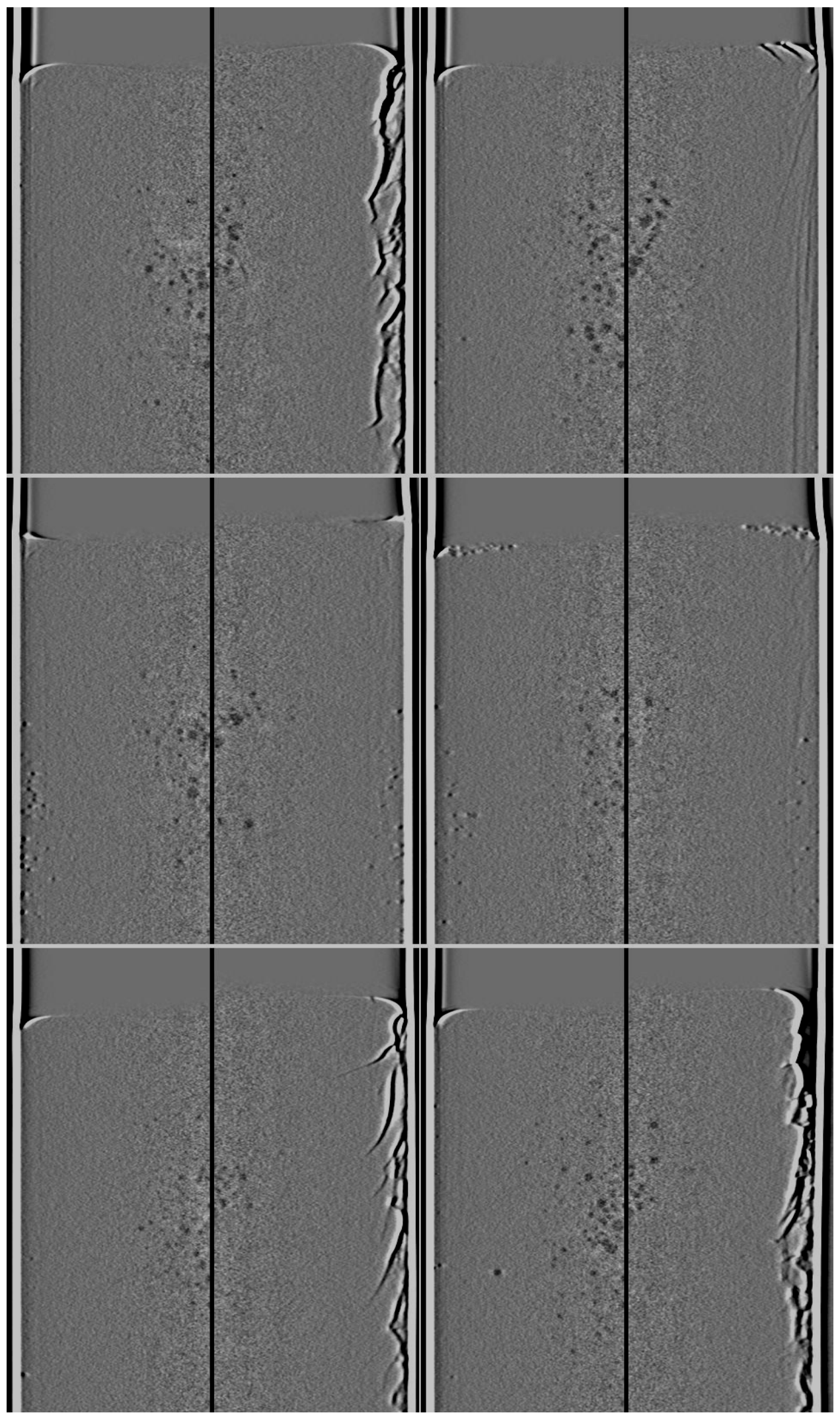

Figure 26. Canister \#2 Top Section Vertical Slices 
WSRC-TR-2006-00015

Revision 0

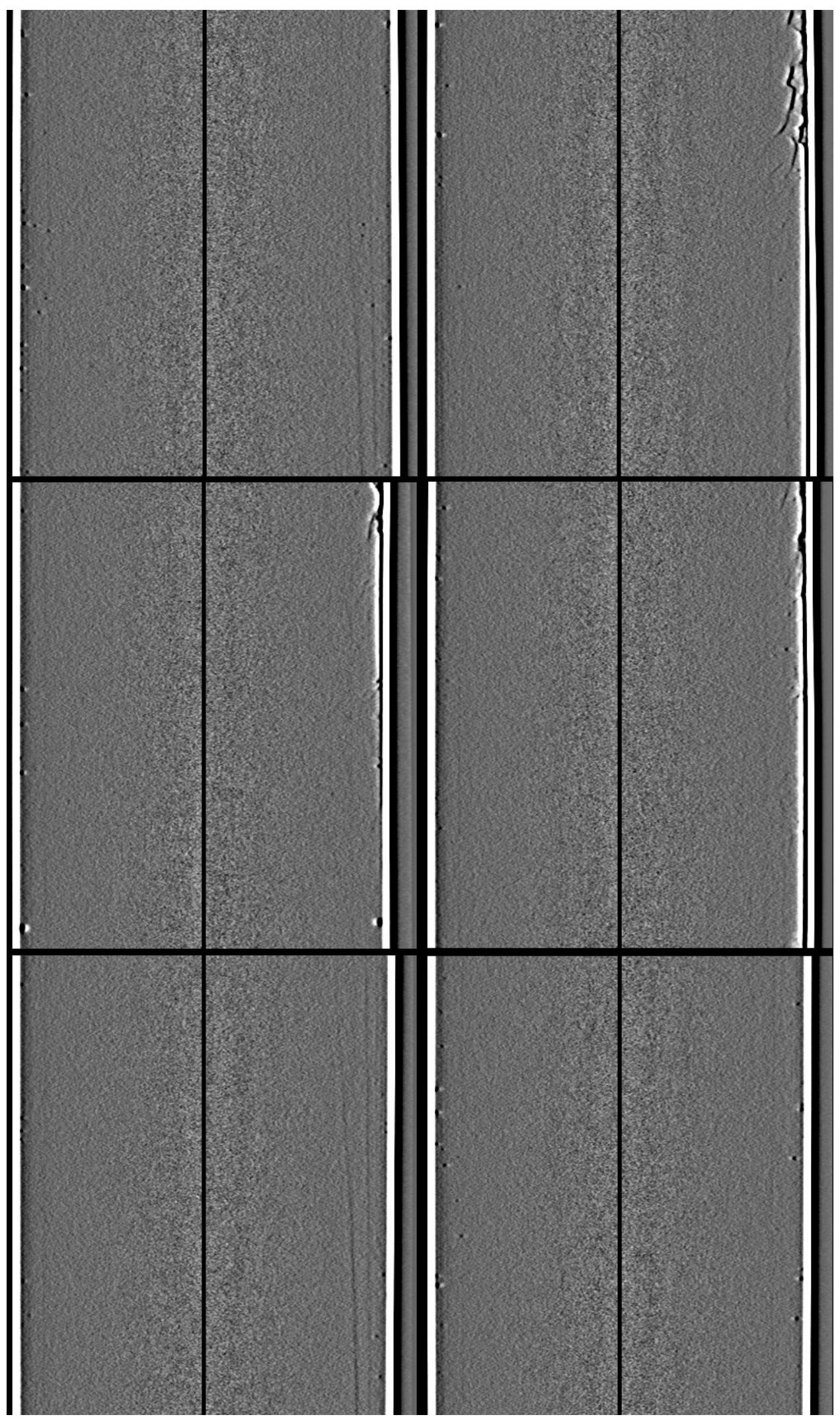

Figure 27. Canister \#2 Middle Section Vertical Slices 
WSRC-TR-2006-00015

Revision 0

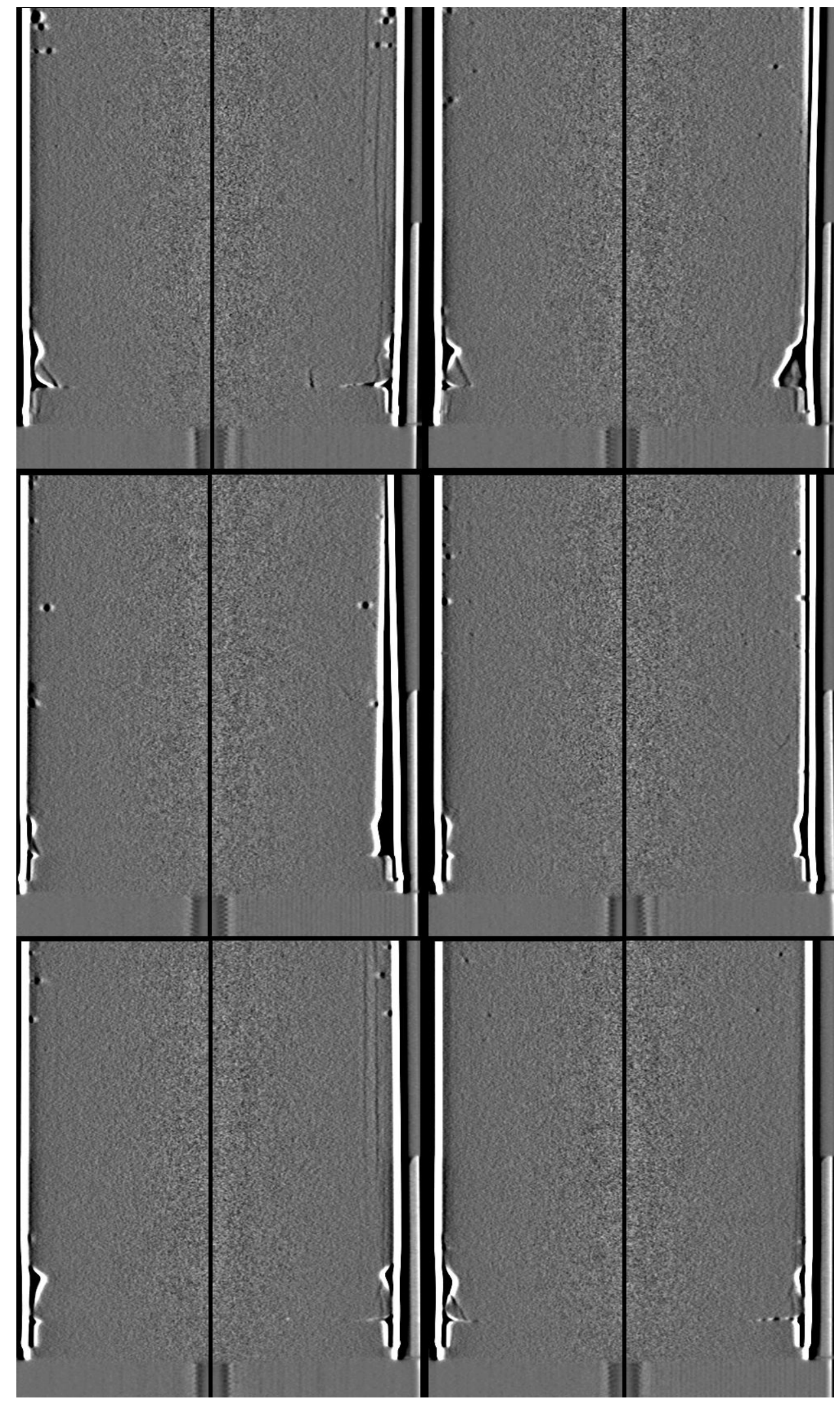

Figure 28. Canister \#2 Bottom Section Vertical Slices 
Can 3 composite CT generated radiographs 0 and 90 degrees views of pre-annealed (left) and post-annealed (right) top, middle and bottom sections.
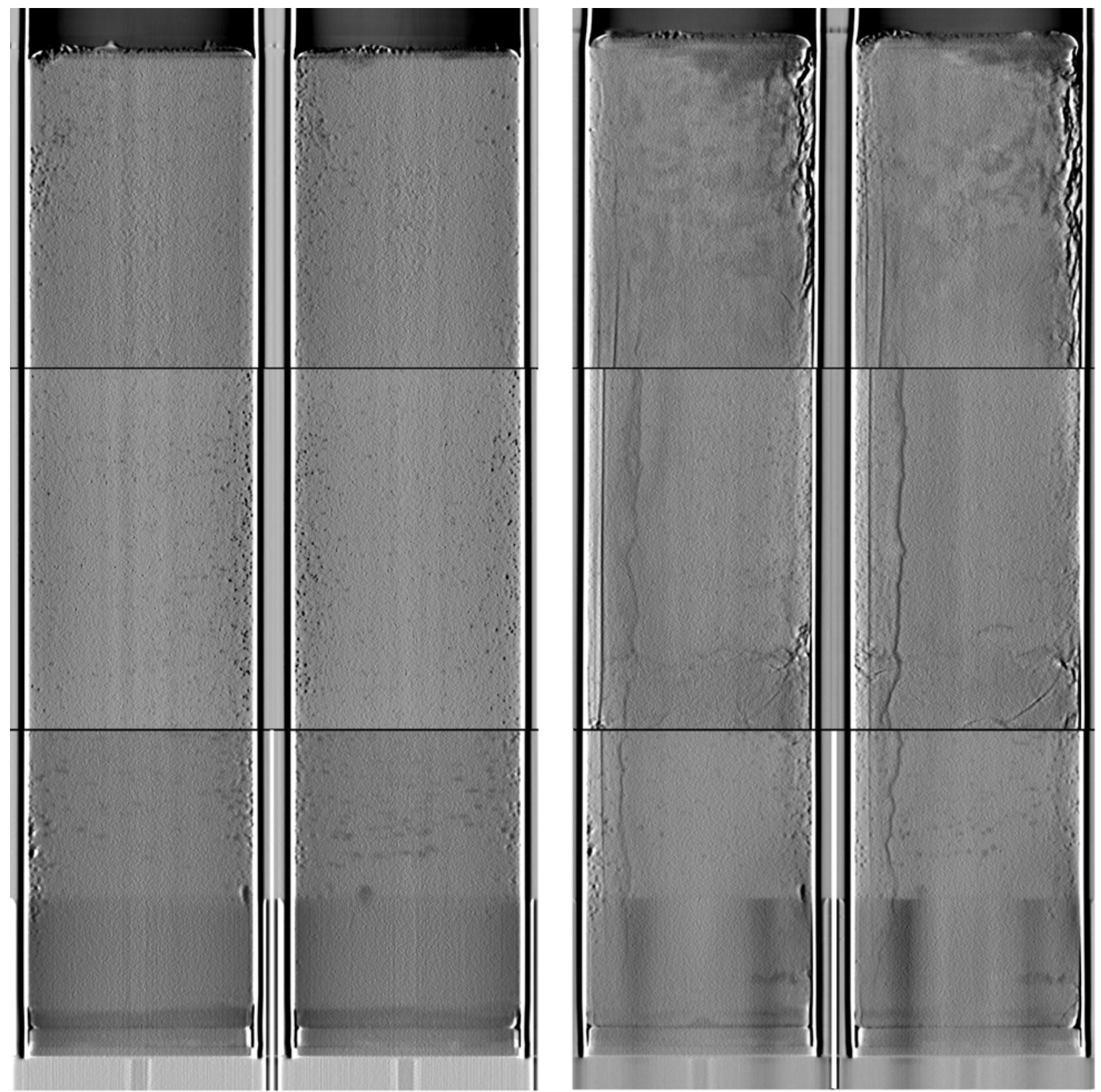

Figure 29. Canister \#3 Composite CT Generated Radiographs 
WSRC-TR-2006-00015

Revision 0
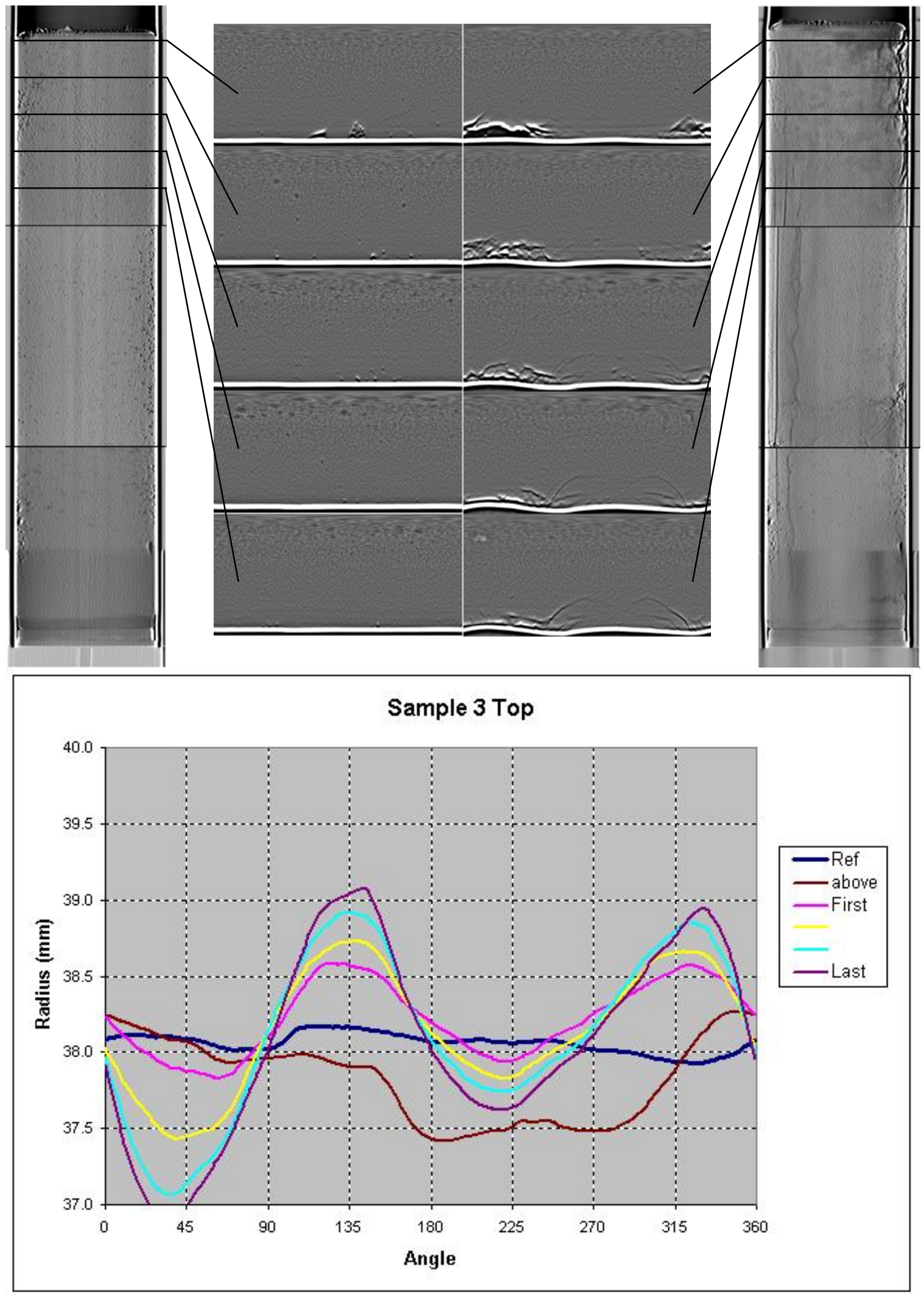

Figure 30. Canister \#3 Top Section Vertical Slices 
WSRC-TR-2006-00015

Revision 0
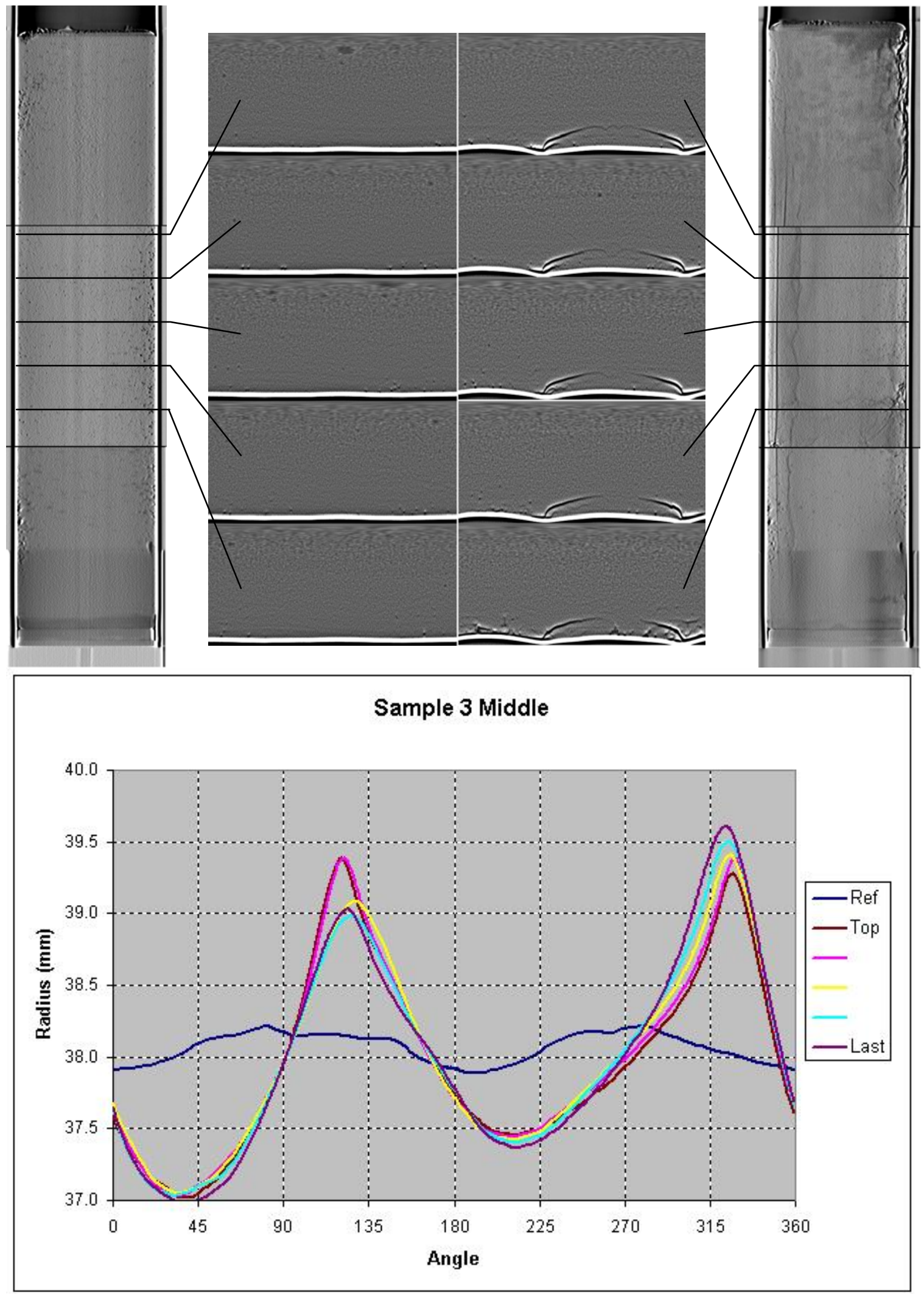

Figure 31. Canister \#3 Middle Section Vertical Slices 
WSRC-TR-2006-00015

Revision 0
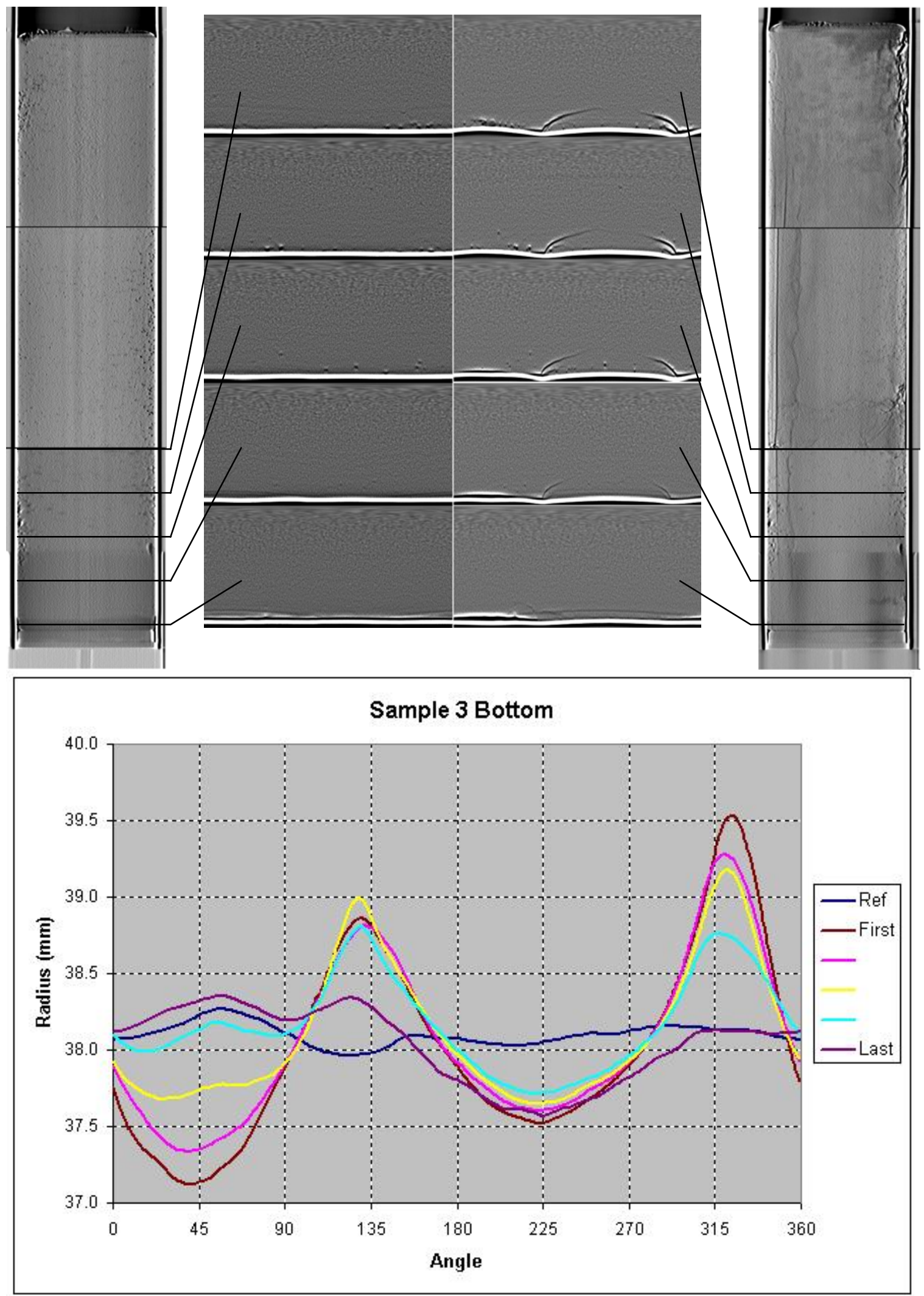

Figure 32. Canister \#3 Bottom Section Vertical Slices 
WSRC-TR-2006-00015

Revision 0

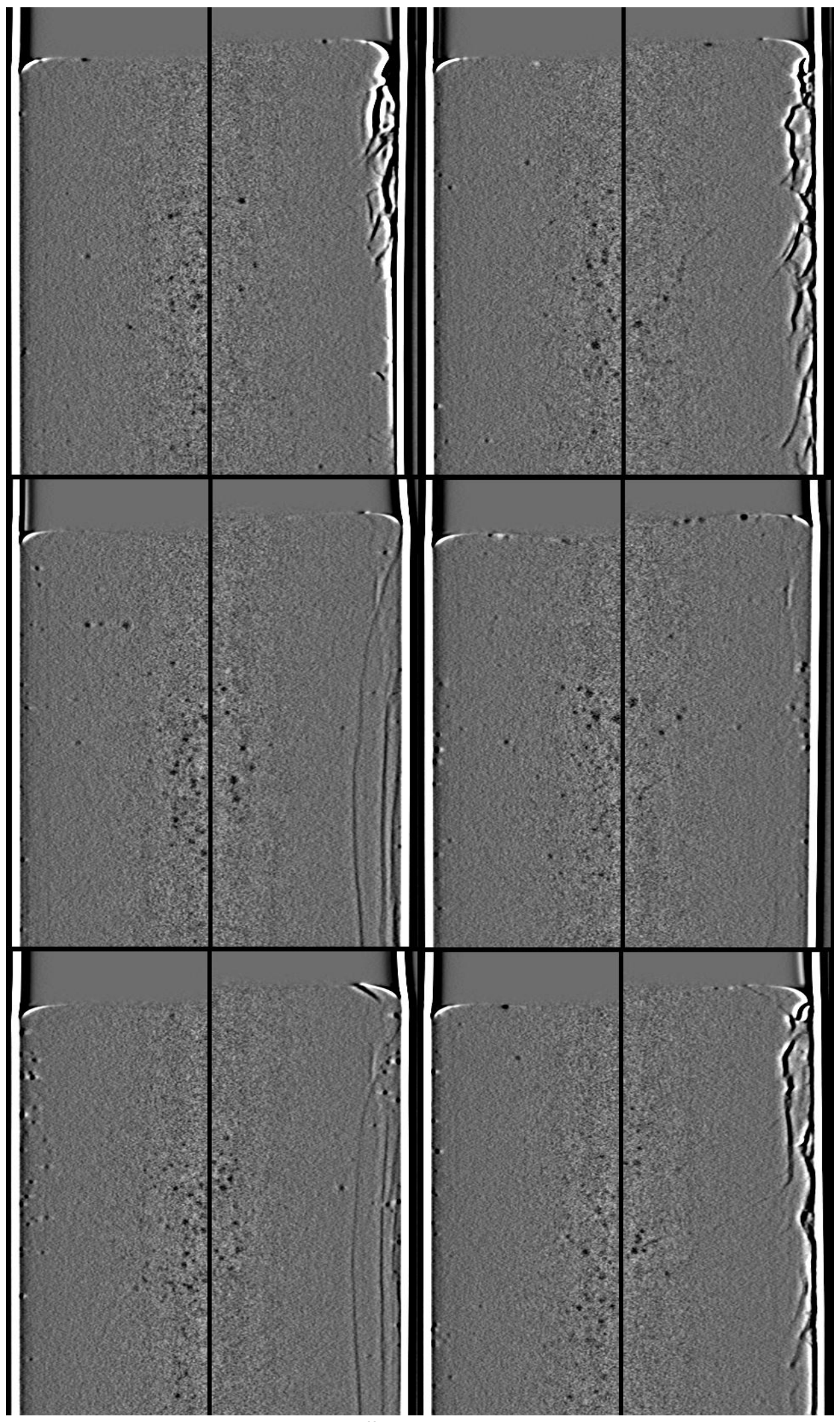

Figure 33. Canister \#3 Top Section Vertical Slices 
WSRC-TR-2006-00015

Revision 0

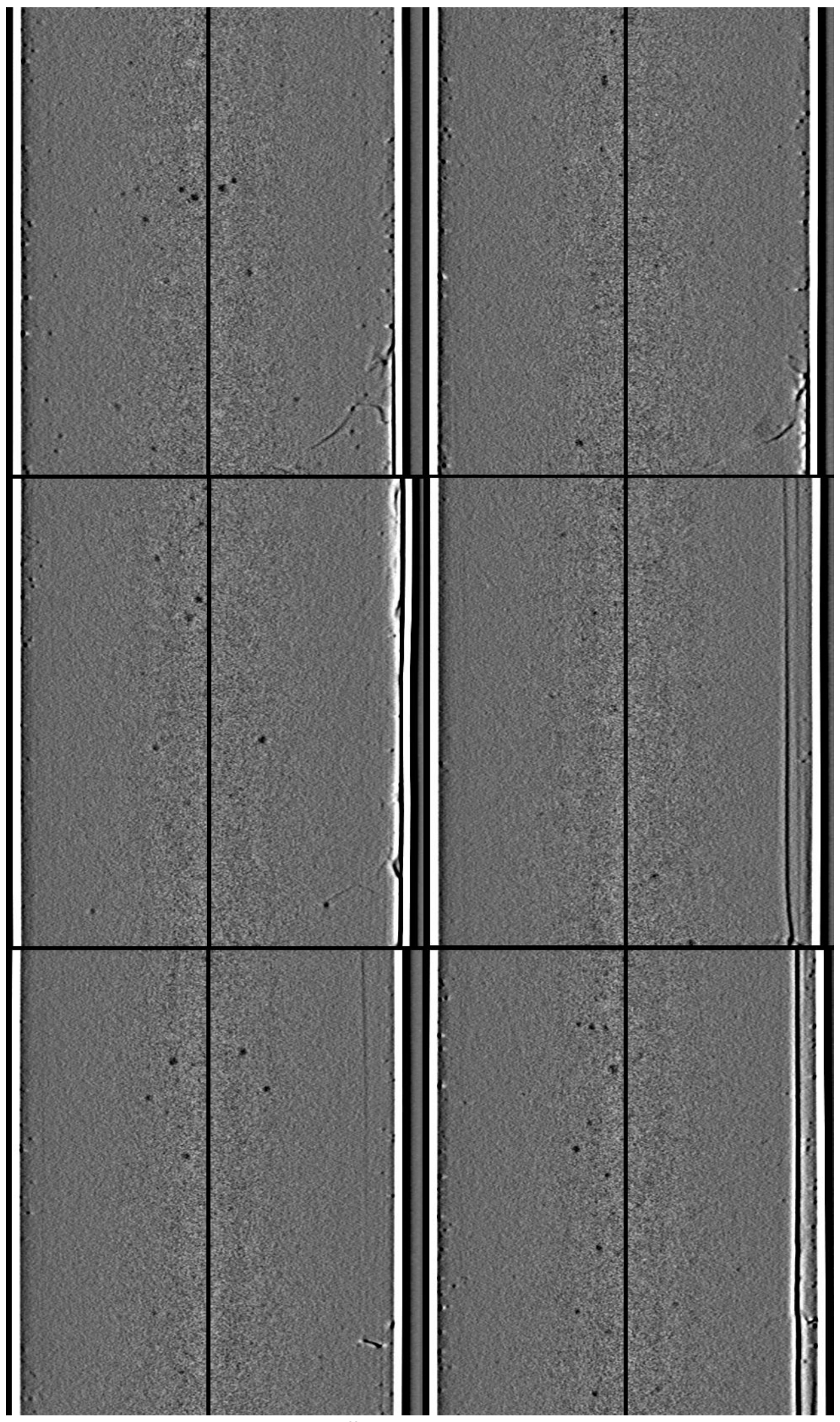

Figure 34. Canister \#3 Middle Section Vertical Slices 
WSRC-TR-2006-00015

Revision 0

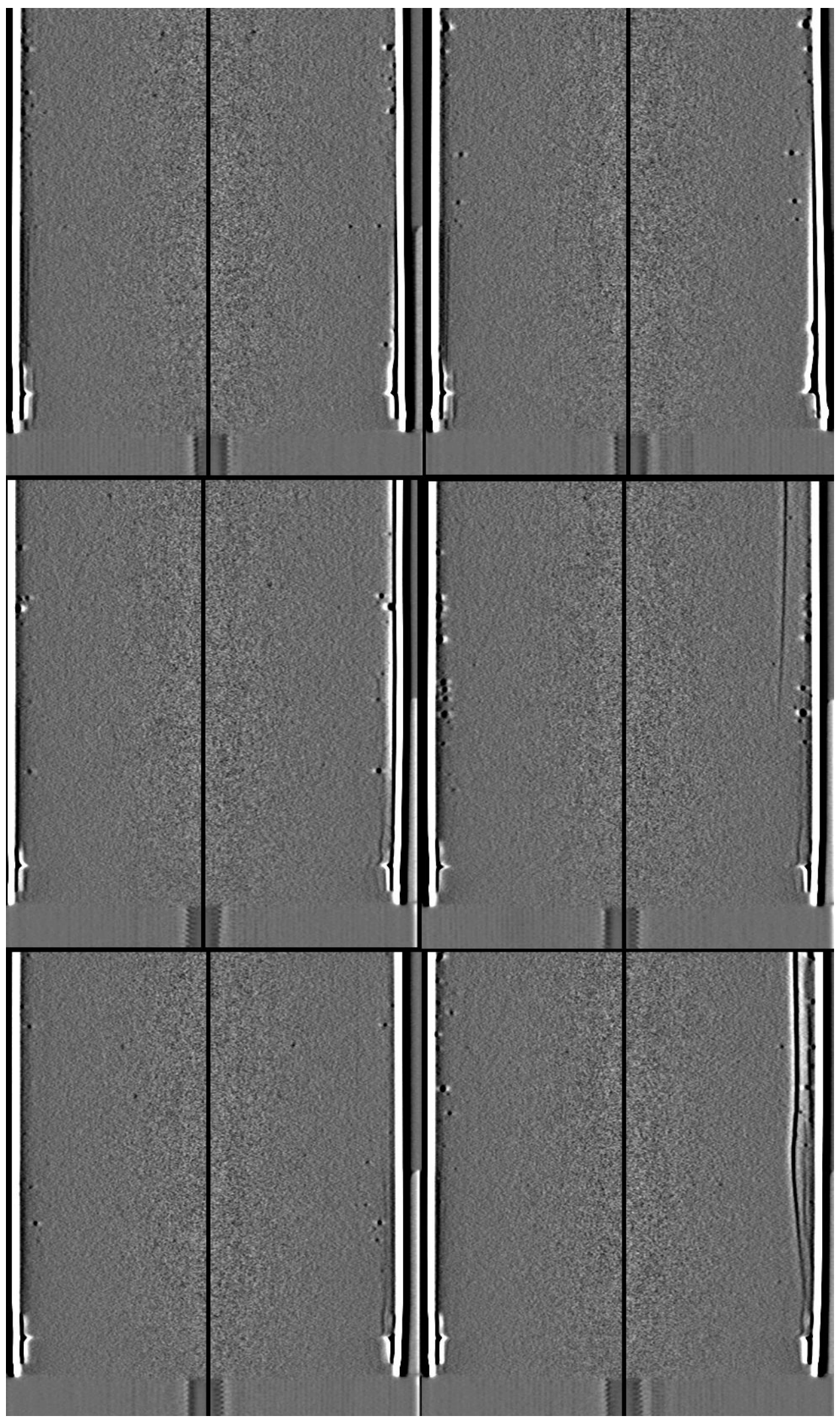

Figure 35. Canister \#3 Bottom Section Vertical Slices 


\subsection{CONCLUSIONS}

Testing conducted on 2.87 inch ID by 19.25 inch tall canisters have shown that thermal stresses and glass/canister interactions result in a 1.9 to 4.1 times increase in surface area as compared to the monolithic geometric surface area. The LaBS Frit B composition glass (with $\mathrm{ZrO}_{2}$ substituted for $\mathrm{Pu}$ ) yielded a clear indication as to the macrocracking that may be expected when small canisters are filled, allowed to cool, and subsequently exposed to thermal cycling similar to that of having molten glass poured around the canister.

Comparison of the digital radiography images taken of the canisters before and following the heat treatment suggests the cracking that occurred within the glass was largely the result of the heat treatment. The cracks that are evident only after the heat treatment emanate from stresses resulting from the canisters being laid horizontally during the heat treatment that resulted in a slight flattening of the canisters.

There is also visual indication that the amount of porosity within the LaBS glass was reduced by the thermal heat treatment, i.e. less voids were present after the heat treatment than before. Also, the height of the glass within the canisters was greater following the heat treatment than before, suggesting the glass began to soften and flow towards the open end of the canisters during heat treatment. Had the canisters been heat treated in a vertical orientation, as will be the arrangement within the DWPF canisters, increased densification (filling voids with glass) of the LaBS glass monolith should occur. As the voids are reduced in size and number as a result of the glass softening, a more complete filling of the canister would be achieved. 


\subsection{REFERENCES}

Plodinec, M.J., 1989, Glass Fracture and DWPF Product Performance. DPST-89-220, Savannah River Site, Aiken, SC 29808.

Peters, R. D., and S. C. Slate, 1981, Fracturing of Simulated High-level Waste Glass in Canisters, PNL-3948, UC-70, Pacific Northwest National, Richland, WA.

Kessler, J.L., 1982, Effect of Cooling Rate, Thermal Expansion, and Waste Loading on Glass Fracture. DPST-83-490, Savannah River Site, Aiken, SC 29808.

Bacon D.H., and B.P. McGrail, 2005, Waste Form Release Calculations for the 2005 Integrated Disposal Facility Performance Assessment, PNNL-15198, Pacific Northwest National Laboratory, Richland, WA.

Smith, M.E., Hovis, G.L., and E.L. Hamilton, 2000, Phase 2 Can-In-Canister Cold Pour Tests for the Plutonium Immobilization Project. WSRC-TR-2000-00408, Savannah River Site, Aiken, SC 29808.

Jones, T.M., 2005, ACTL CIM-2 Process LaBS Frit B Cullet To Fill Prototype Pu Vit Canisters. SRNL-ITS-2005-00219, Rev.0, Savannah River Site, Aiken, SC 29808.

Marra, J. C., D. K. Peeler, and C. M. Jantzen, "Development of Alternative Glass Compositions for Vitrification of Excess Plutonium," WSRC-TR-06-00031, Washington Savannah River Company, Aiken, SC, 2006. 


\subsection{ACKNOWLEDGEMENTS}

The authors wish to acknowledge the efforts of many who contributed to the completion of this task. Irene Reamer, Phyllis Workman and Frances Williams supported the task by preparing glass cullet from LaBS Frit B batch chemicals, and assisted with the procurement of cullet from a commercial vendor. David Best and his staff at the SRNL Mobile Laboratory provided analytical support with ICP atomic emission spectroscopy data for feed batch and glass product samples. Kurt Sexton and Gary Dobos of the SRNL Glass Shop supported the task by mechanically sectioning the prototypic canisters for visual inspection of internal cracks and voids within the LaBS glass product. David Healey performed the visual inspection of the sectioned canisters to determine the degree of cracking within the LaBS glass product. And finally, Don Miller and Mike Stone were helpful in support of the operation of the Cylindrical Induction Melter and the filling of the prototypic canisters with the LaBS glass. 


\subsection{APPENDIX}

\subsection{ACTL CIM Dimensions and Thermocouple Locations}

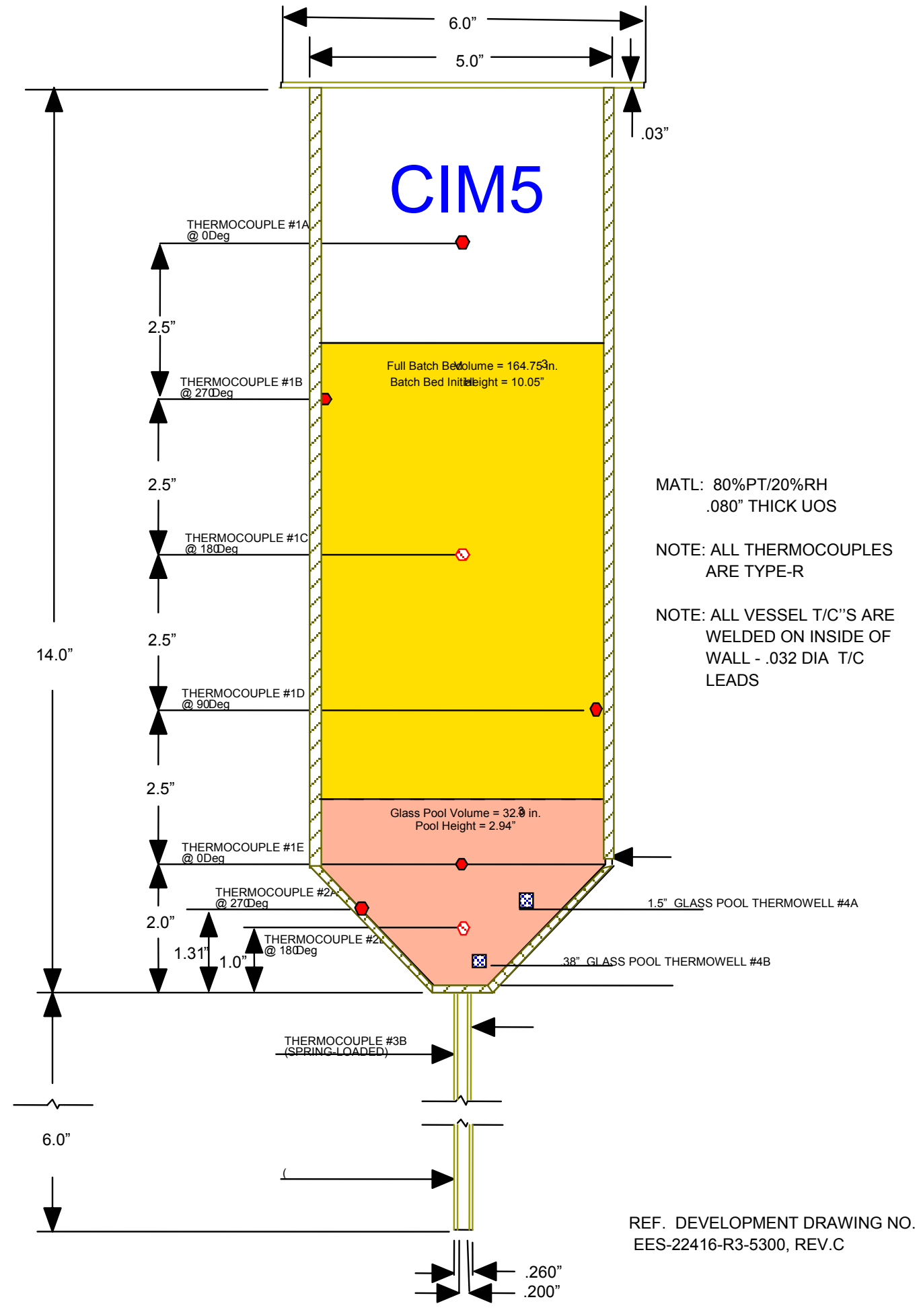


7.2 Prototypic Pu Vitrification Canisters Dimensions
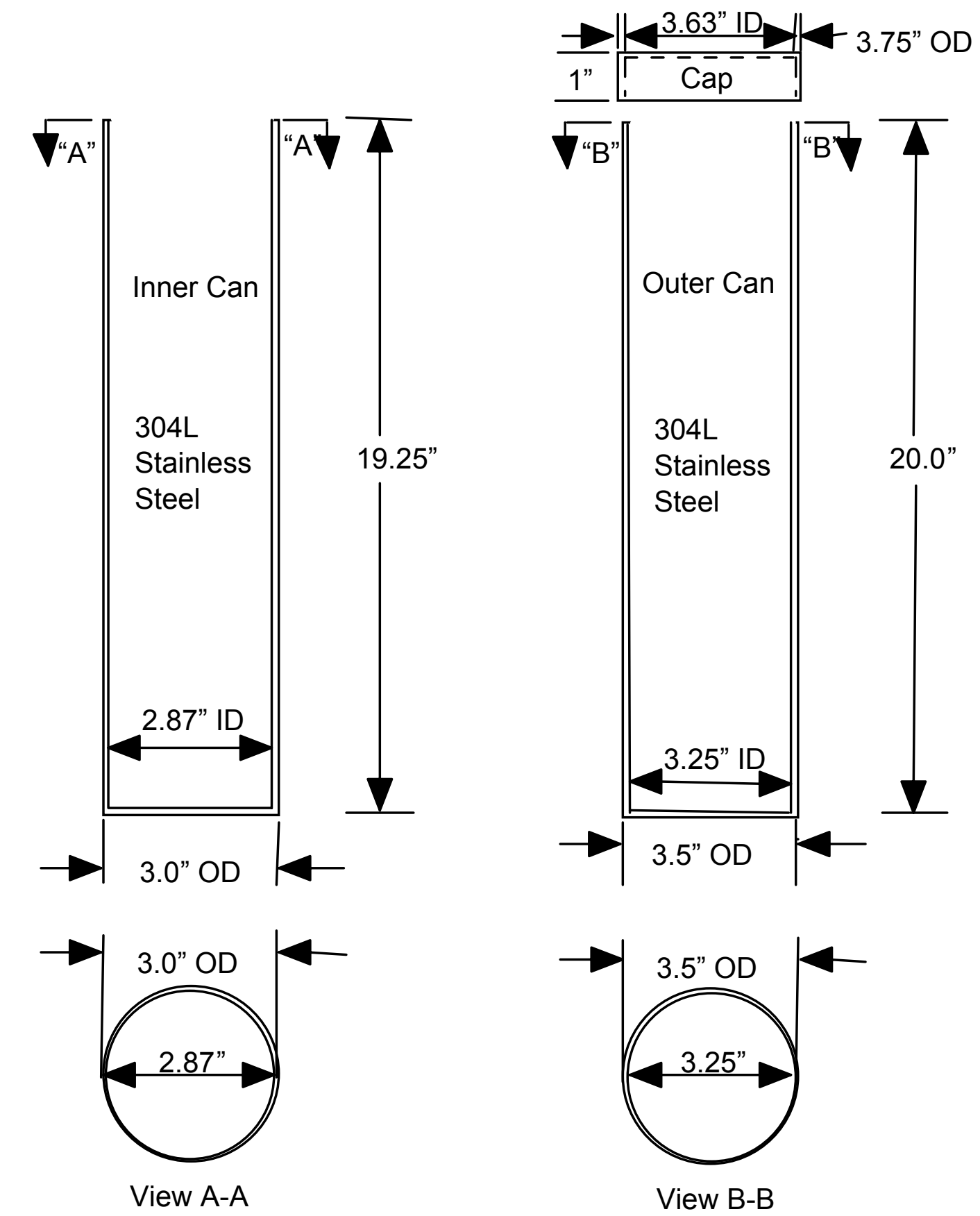

View B-B 
7.3 Prototypic Pu Vitrification Canisters Sectioned Dimensions

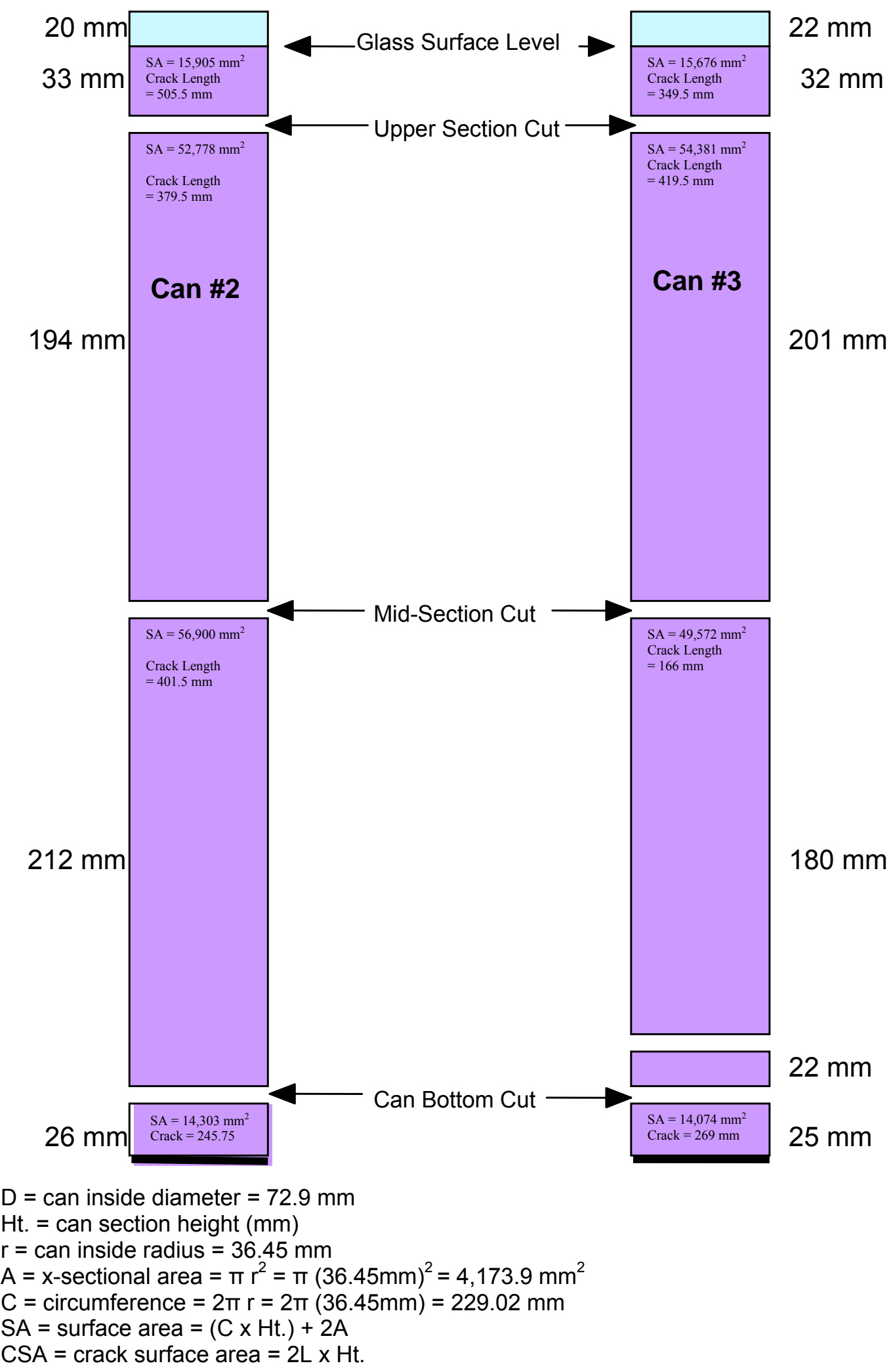




\subsection{Prototypic Canisters Radiography Section Dimensions}

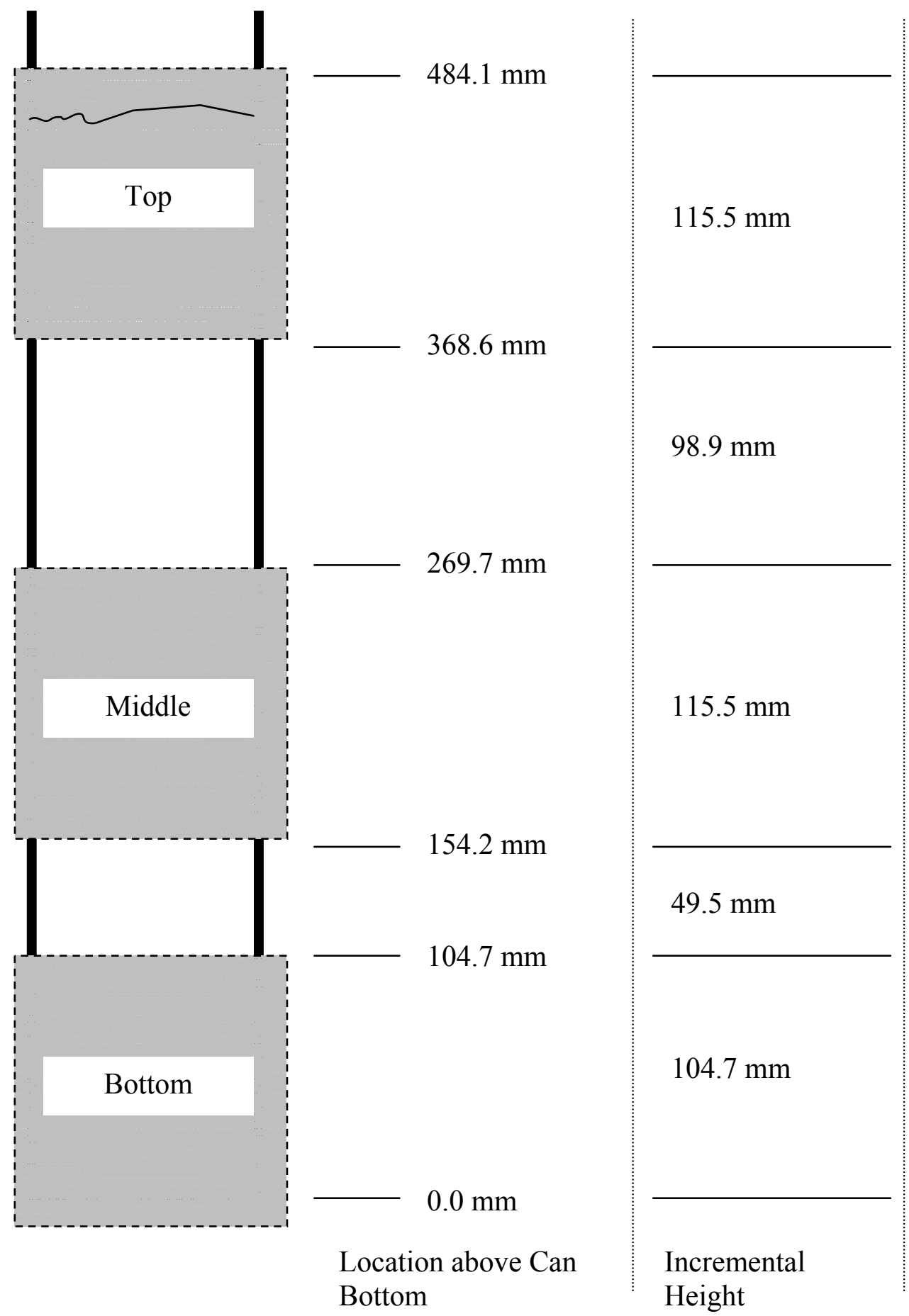

